\title{
Change of apparent segmentation of the San Andreas fault around Parkfield from space geodetic observations across multiple periods
}

\author{
Sylvain Barbot, ${ }^{1}$ Piyush Agram, ${ }^{2}$ and Marcello De Michele ${ }^{3}$ \\ Received 22 June 2013; revised 19 October 2013; accepted 6 November 2013; published 9 December 2013.
}

[1] Sequences of earthquakes are commonly represented as a succession of periods of interseismic stress accumulation followed by coseismic and postseismic phases of stress release. Because the recurrence time of large earthquakes is often greater than the available span of space geodetic data, it has been challenging to monitor the evolution of interseismic loading in its entire duration. Here we analyze large data sets of surface deformation at different key episodes around the Cholame, Parkfield and creeping segments of the San Andreas Fault that show evidence of significant deceleration of fault slip during the interseismic period. We compare the average fault slip rates before and after the $2004 M_{w} 6$ Parkfield earthquake, in the 1986-2004 and 2006-2012 periods, respectively, avoiding 2 years of postseismic deformation after 2004. Using a combination of GPS data from the Plate Boundary Observatory, the Southern California Earthquake Center Crustal Motion Map and the Bay Area Velocity Unification networks and interferometric synthetic aperture radar from the Advanced Land Observing Satellite (ALOS) and Envisat satellites, we show that the area of coupling at the transition between the Parkfield and Cholame segments appears larger later in the interseismic period than it does earlier on. While strong plate coupling is uniform across the Parkfield and Cholame segments in the 1986-2004 period, creep occurs south of the 2004 epicenter after 2006, making segmentation of the San Andreas Fault south of Parkfield more clearly apparent. These observations indicate that analyses of surface deformation late in the earthquake cycle may overestimate the area of plate coupling. A fault surface creeping much below plate rate may in some case be a region that does not promote earthquake nucleation but rather just be at a slower stage of its evolution. Our analysis also shows signs of large variation of slip velocity above and below plate rate in the creeping segment indicating that cycles of weakening and hardening can also be at play in dominantly aseismic areas.

Citation: Barbot, S., P. Agram, and M. De Michele (2013), Change of apparent segmentation of the San Andreas fault around Parkfield from space geodetic observations across multiple periods, J. Geophys. Res. Solid Earth, 118, 6311-6327, doi:10.1002/2013JB010442.

\section{Introduction}

[2] The Cholame, Parkfield and creeping segments of the San Andreas Fault (SAF) form the northern boundary of the great M 7.91857 Fort Tejon earthquake and its potential foreshocks [Wood, 1955]. The Cholame segment was

Additional supporting information may be found in the online version of this article.

${ }^{1}$ Earth Observatory of Singapore, Nanyang Technological University, Singapore, Singapore.

${ }^{2}$ California Institute of Technology, Pasadena, California, USA.

${ }^{3}$ Bureau de Recherche Géologique et Minière, Orleans, France.

Corresponding author: S. Barbot, Earth Observatory of Singapore, Nanyang Technological University, Singapore, Singapore. (sbarbot@ntu.edu.sg)

C2013. American Geophysical Union. All Rights Reserved.

2169-9313/13/10.1002/2013JB010442 ruptured during the 1857 event [Sieh, 1978a], and there is evidence of three similar earthquakes since $1000 \mathrm{~A}$. D. [Young et al., 2002]. Offset of geological markers indicates a late Holocene slip rate of $26.2+6.4 / 4.3 \mathrm{~mm} / \mathrm{yr}$ near Parkfield [Toké et al., 2011] and $33.9 \pm 2.9 \mathrm{~mm} / \mathrm{yr}$ near Wallace Creek [Sieh and Jahns, 1984]. Since the last rupture, about $5 \mathrm{~m}$ of slip deficit accumulated at crustal depths and Cholame may soon be the host of another large devastating earthquake [Wesnousky, 1986]. The Parkfield segment is a transition zone between the locked Cholame segment and the creeping section to the northwest and is the site of at least six $M_{w} \sim 6$ earthquakes since 1857 in 1881, 1901, 1922, 1934, 1966, and 2004 [Bakun and McEvilly, 1984; Bakun and Lindh, 1985; Bakun et al., 2005]. Because of the short recurrence time of the $M_{w} 6$ earthquakes, between 12 and 38 years, Parkfield is an ideal place to study earthquakes and test the potential of their forecast [e.g., Roeloffs and Langbein, 
1994; Barbot et al., 2012]. The creeping segment, starting a few kilometers north of the $1966 M_{w} 6$ Parkfield epicenter, has had no earthquakes larger than $M_{w} 4$ in the past 65 years and has been creeping at depth at a rate of $33 \mathrm{~mm} / \mathrm{yr}$, based on geodetic data in the 1969-1976 period [Thatcher, 1979; Burford and Harsh, 1980].

[3] It is important to understand the mechanics of faulting at this crucial location of the SAF to address both fundamental questions about earthquake physics and mitigate seismic hazards, but many aspects of the kinematics of the SAF remain unexplained.

[4] Shallow creep in the creeping section is higher but in some places markedly slower than plate rate at greater depths [Thatcher, 1979; Johanson and Bürgmann, 2005; Rolandone et al., 2008; Ryder and Bürgmann, 2008]. The implications of this shallow slip deficit is not fully understood and may be the result of a process of stress buildup released in earthquakes [Toppozada et al., 2002], spontaneously nonsteady fault slip due to a particular friction behavior in a manner similar to slow slip events of slow earthquakes [e.g., Rogers and Dragert, 2003; Liu and Rice, 2005; Miyazaki et al., 2006; Ito et al., 2007] or transient loading from earthquakes on neighboring segments [e.g., Ben-Zion et al., 1993].

[5] Paleoseismic studies indicate that the 1857 Fort Tejon earthquake was preceded by two foreshocks in an area that includes the Parkfield and creeping segments [Sieh, 1978a, 1978b; Toppozada et al., 2002]. There is a possibility that the foreshock activity includes events similar to the $M_{w} 6$ earthquake sequence at Parkfield and that these earthquakes can trigger a larger rupture along the Cholame and Carrizo segments. Because many Parkfield earthquakes did not trigger a larger event, the mechanics behind this scenario implies a soft barrier between the Parkfield and Cholame segments, which would function as an efficient arrest to rupture only on occasion in history [e.g., Kaneko et al., 2010].

[6] Recently, Barbot et al. [2012] presented a physical model of earthquakes at Parkfield based on rate-and-state friction that can explain many aspects of seismological and geodetic observations. The model assumes that the seismogenic zone is delineated by persistent streaks of seismicity and that the 1966 and 2004 events started at the northern and southern boundaries of the seismogenic zone, respectively. The southern end of the seismogenic zone is not fully apparent from inversion of geodetic data before the 2004 earthquake [Segall and Du, 1993; Bakun et al., 2005; Murray and Segall, 2005], and documenting the presence of this potential boundary can have important implications on the mechanics of the earthquake cycle at the Parkfield and Cholame segments. In particular, it is important to know how the series of $M_{w} 6$ earthquakes at Parkfield are arrested and initiated at the southern end and what are the mechanical properties of the boundary between the Cholame and Parkfield segments.

[7] To address these questions, we use geodetic data of the interseismic period of the Parkfield earthquake cycle (Figure 1). We use average velocities of surface displacement derived from analysis of continuous GPS times series and interferometric synthetic aperture radar (InSAR). Many analyses of InSAR and GPS have been successful at constraining slow interseismic deformation across faults [Wright et al., 2004; Fialko, 2006; Cavalié et al., 2008;

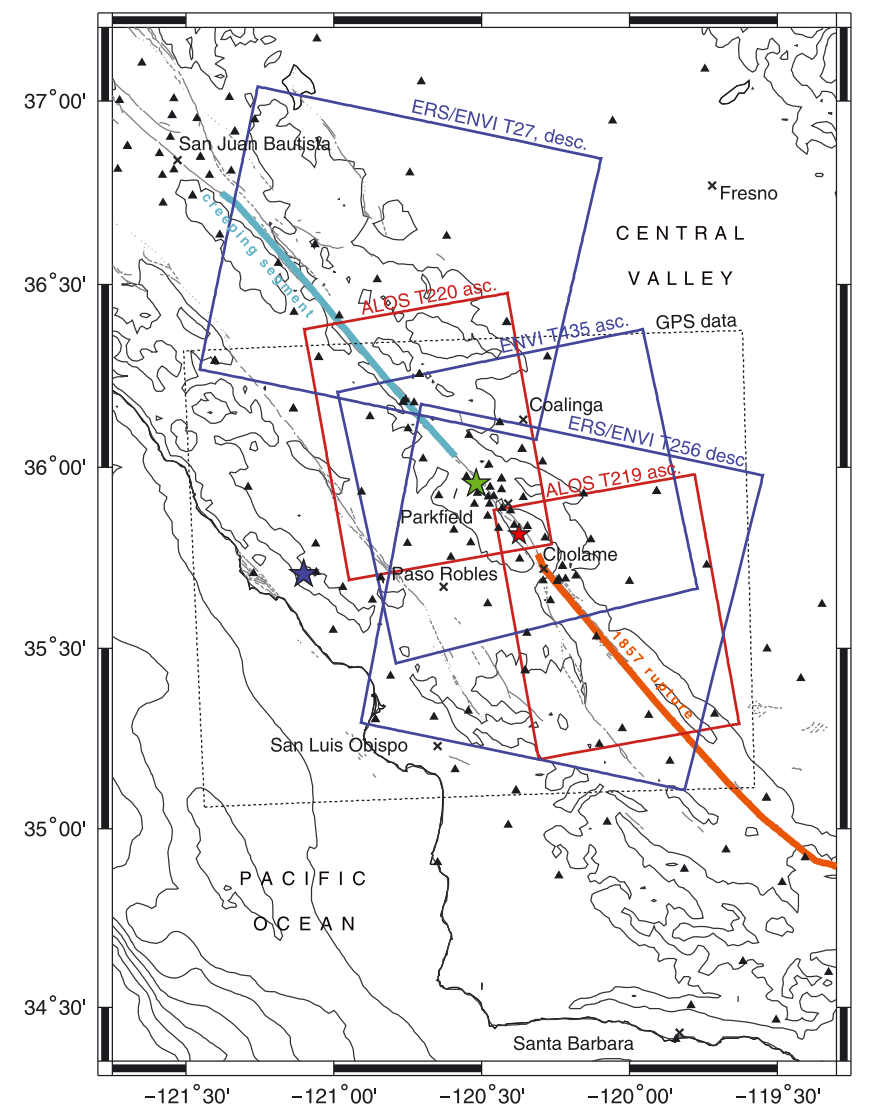

Figure 1. Area of study, including the Cholame-Carrizo, Parkfield and creeping segments of the San Andreas Fault. The 1966 and 2004 Parkfield and the 2003 San Simeon earthquakes are shown in green, red, and blue stars, respectively. The local topography/bathymetry is shown in grey profiles. The subset of continuous GPS stations used in this study is contained in the black dashed box. The footprints of the Envisat, European Remote-Sensing Satellite (ERS), and ALOS interferograms used in the study are indicated by the colored boxes.

Jolivet et al., 2008; Elliott et al., 2011; Wang et al., 2009; Fay and Humphreys, 2005; Lundgren et al., 2009; Bell et al., 2011; Lindsey and Fialko, 2013; Jolivet et al., 2012], and our work extends studies focused on the northern termination of the central SAF section [Rolandone et al., 2008; Ryder and Bürgmann, 2008; Johanson and Bürgmann, 2010]. Because the apparent interseismic velocity can change appreciably during the interseismic cycle [e.g., Tse and Rice, 1986; Lapusta et al., 2000; Barbot et al., 2012; Lapusta and Barbot, 2012], we compare interseismic fault slip rates before and after the 2004 Parkfield earthquake. This allows us to build a more complete picture of the range of possible behavior in the interseismic period.

[8] The manuscript is organized as follows. In sections 2 and 3, we describe the processing of InSAR data and our inversion method. In sections 4 and 5 , we present the fault slip rates in the 1986-2004 and 2006-2012 periods, respectively. We discuss the implications for earthquake mechanics in section 6 . 
Table 1. Table of all SAR Data Used in This Manuscript ${ }^{\mathrm{a}}$

\begin{tabular}{lccccc}
\hline Sensor & Geometry & Track & Frame & $\mathrm{N}_{\text {SAR }}$ & $\mathrm{N}_{\text {InSAR }}$ \\
\hline \multicolumn{2}{l}{ Pre-earthquake (1992-2004) } & & & & \\
\hline ERS & desc. & 27 & 2871 & 43 & 47 \\
ERS & desc. & 256 & 2889 & 41 & 80 \\
ENVI & asc. & 435 & 711 & 5 & 6 \\
\hline \multicolumn{2}{l}{ Post earthquake (2006-2010) } & & & & \\
\hline ENVI & desc. & 27 & 2871 & 23 & 34 \\
ERS & desc. & 256 & 2889 & 4 & 2 \\
ENVI & desc. & 256 & 2889 & 11 & 20 \\
ENVI & asc. & 435 & 711 & 22 & 66 \\
ALOS & asc. & 220 & 710 & 16 & 83 \\
ALOS & asc. & 219 & 700 & 16 & 59 \\
\hline
\end{tabular}

${ }^{a} \mathrm{~N}_{\mathrm{SAR}}$ is the number of individual SAR images. $\mathrm{N}_{\text {InSAR }}$ is the number of independent interferograms.

${ }^{b}$ ascending (asc.) and descending (desc.) images have different and complementary look angles.

\section{InSAR Data and Processing}

[9] In this work, we use a rich data set of interferograms constructed from synthetic aperture radar (SAR) images acquired by the ERS, Envisat, and ALOS satellites and spanning more than 15 years using both C-band $(56 \mathrm{~mm})$ and L-band $(23 \mathrm{~cm})$ radar wavelength. Figure 1 shows the frame boundaries of the five different sets of SAR images used in this study. All C-band data, from the ERS and Envisat satellites, are obtained from the WInSAR and the European Space Agency SAR archives and the ALOS Phased Array type L-band Synthetic Aperture Radar (PALSAR) data are obtained from the Alaska SAR Facility's DAAC. Pre-earthquake data (1992 to 2004) were mostly acquired by the ERS-1 and ERS-2 satellites, whereas Envisat and ALOS satellites account for the dense temporal coverage after the Parkfield earthquake (2006 to 2010). Table 1 summarizes all the SAR data used in this work, and the corresponding baseline plots are included in Figure 2 and the supporting information.

[10] Subsets of our large SAR data set have been used in previously published studies over our region of interest. Johanson et al. [2006] studied the coseismic and immediate postseismic deformation after the 28 September 2004 Parkfield earthquake using Radarsat and a more limited set of Envisat interferograms. Ryder and Bürgmann [2008] applied stacking techniques to a set of 12 interferograms covering the creeping section of the San Andreas Fault (Track 27) and observed that the study area (Figure 1) is characterized by absence of strongly reflecting urban targets and severe decorrelation due to vegetation. De Michele et al. [2011] analyzed data from Track 256 to derive a detailed surface velocity field prior to the Parkfield earthquake. We increase the number of interferometric observations before the earthquake by including a larger set of interferograms from Track 27 and a few Envisat interferograms from Track 435 (see Table 1 and Figure S1 in the supporting information). The SAR images prior to the $2004 M_{w} 6.0$ Parkfield earthquake (pre-EQ) were primarily acquired on descending passes. The number of post-EQ C-band interferograms per track is smaller than the corresponding pre-EQ data set. However, ascending pass L-band images from the ALOS PALSAR instrument, launched in 2006, make up for reduced number of observations by imposing better geometric constraints.

\subsection{InSAR Processing}

[11] The ERS and Envisat interferograms are individually processed using the Repeat Orbit Interferometry PACkage (ROI-PAC) package [Rosen et al., 2004] and then coregistered against a master ERS SAR scene. ERS scenes affected by the gyroscope failure in 2001 are preprocessed to determine the correct Doppler ambiguities before processing with ROI-PAC. Despite monthly acquisitions, a large number of the ERS-2 scenes acquired after 2001 could not be used due to large doppler baselines. All the C-band interferograms are processed at a posting of roughly $100 \mathrm{~m}$ (4 looks in range and 20 looks in azimuth). The ALOS PALSAR interferograms are processed using Stanford University's mocomp processor [Zebker et al., 2010] to a common imaging geometry. All the fine-beam dual (FBD) mode scenes are upsampled to full resolution after focusing and before coregistration. The ALOS interferograms are also generated at a posting of $100 \mathrm{~m}$ (12 looks in range and 28 looks in azimuth).

[12] All the interferograms are filtered using a Goldstein filter [Goldstein and Werner, 1998] of moderate strength and individually unwrapped using Statistical-cost, Network-flow Algorithm for Phase Unwrapping (SNAPHU) [Chen and Zebker, 2002]. All the post-EQ interferograms are deramped using daily GPS solutions from the Scripps Observatory and Permanent Array Center (SOPAC) archive (sopac.ucsd.edu). All the pre-EQ interferograms are deramped by removing the best fitting plane from the unwrapped phase, due to the absence of continuous GPS stations between 1992 and 1994. A large number of interferograms were initially generated, and only a subset (Table 1) with greater than $60 \%$ spatial coverage (coherence greater than 0.25 ) over the entire frame

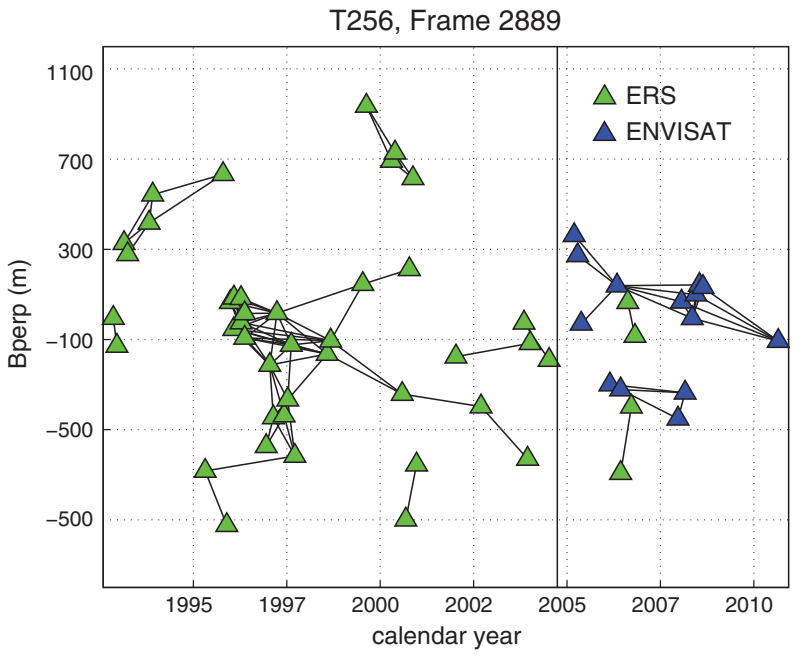

Figure 2. SAR acquisitions (triangles) and interferograms (black segments) of ERS and Envisat data considered in this study for track 256 and frame 2889. See Figures S1 for a description of other SAR data used in the study. 
is retained for analysis with the Multiscale Interferometric Time Series (MInTS) technique [Hetland et al., 2012].

\subsection{MInTS Time Series Processing}

[13] We first analyzed the C-band interferogram stacks using an integral spline formulation similar to Hetland et al. [2012], and we observed that the associated uncertainties are larger than $1 \mathrm{~cm}$ possibly due to (1) insufficient redundancy of the C-band interferogram networks (compare number of coherent interferograms versus number of SAR images in Table 1) and (2) presence of independent subnetworks of coherent interferogram clusters (supporting information) particularly after 2001. Direct time series estimation for the ALOS PALSAR stacks is not carried out due to the limited number of SAR acquisitions. We apply the MInTS technique to determine a constant line of sight velocity term and a seasonal signal amplitude with a 1 year period for each of the interferogram stacks at a spatial resolution of $100 \mathrm{~m}$. Assuming a simplified temporal model for deformation allows us to overcome the rank deficiency issues arising due to disconnected interferogram subnetworks. The MInTS technique has two advantages: (1) it allows us to interpolate over small decorrelated regions in space and (2) the use of wavelets reduces the impact of atmospheric phase contributions in the estimated deformation parameters by minimizing the effect of spatial and temporally decorrelated signals. The interpolation capability allowed us to increase the number of viable interferograms compared to other stacking techniques applied over the same region. We also estimate uncertainties associated with our simple temporal model based on the residuals of the fit to the temporal evolution and use the information to mask out noisy pixels in the velocity maps before modeling. Finally, all the InSAR data are downsampled to a posting of $2 \mathrm{~km}$ before modeling.

\subsection{Estimation of Uncertainties}

[14] We use a data-driven leave-one-out bootstrap approach to determine the uncertainties in the estimated temporal model parameters. These model parameters could represent piecewise linear functions [Berardino et al., 2002] leading to direct estimation of the deformation time series or a set of temporal functions as is typically used in GPS processing [Bock et al., 1997; Wdowinkski et al., 1997; Herring, 1999] or MInTS [Hetland et al., 2012]. For each frame, subsets of interferograms are generated by leaving out observations corresponding to a SAR scene one at a time, and a set of temporal model parameters are estimated for each of the subsets. The mean and the standard deviation of the estimated parameters are interpreted as the nominal value and the associated uncertainty.

\section{Joint Inversion of GPS and InSAR Data}

[15] In this section, we explain our method to estimate the distribution of slip rates on various faults using InSAR and GPS data simultaneously. GPS average velocities are relative to an arbitrary reference frame, which can vary among different networks. That adds a component to the velocity vectors that cannot be explained by local fault motion. An incorrect description of the reference frame of the data can bias the inversion result, so it can be advantageous to find a formulation of the inverse problem that is independent of the reference frame. Likewise, InSAR line of sight (LOS) measurements are relative to an unknown range and may suffer from orbital errors. We test two methods to mitigate these effects. In a first method, we include the reference frame of the GPS networks and the orbital error of InSAR in the inversion so that the effects of fault displacement and other contributions can be separated. In a second method, we use the baseline velocity between pairs of GPS stations and the gradient of the LOS displacements to constrain fault slip.

\subsection{Case of Absolute GPS and InSAR Velocity}

[16] For each period considered, we jointly invert InSAR data from all tracks and GPS average velocities from an arbitrary number of separate networks for slip rate on faults, dilatational opening of point sources, and other nontectonic parameters. We estimate the optimal orbital errors and GPS reference frames part of a global inversion where slip on faults and other parameters are optimized simultaneously. The geodetic data reduction can be formulated as the minimization problem:

$$
\tilde{\mathbf{m}}=\min _{\mathbf{m}}\left\{\|\mathbf{h}-\mathbf{H} \mathbf{m}\|^{2}\right\}
$$

subject to

$$
\mathbf{A} \mathbf{m} \geq 0
$$

bounded in the range $\mathbf{l} \leq \mathbf{m} \leq \mathbf{u}$, where $\tilde{\mathbf{m}}$ is the vector of optimized parameters, including fault slip rates, and $\mathbf{m}$ is the model space. Diagonal matrix A contains ones for fault slip parameters and 0 for all other parameters. The target vector is formed by a combination of data and constraints:

$$
\mathbf{h}=\left(\begin{array}{l}
\mathbf{d} \\
\mathbf{0}
\end{array}\right)
$$

Similarly, $\mathbf{H}$ is a combination of the design matrix $\mathbf{G}$ and the smoothing operator $\mathbf{D}$ :

$$
\mathbf{H}=\left(\begin{array}{c}
\mathbf{G} \\
\text { D }
\end{array}\right) .
$$

We use lower and upper bounds on the solution, $\mathbf{I}$ and $\mathbf{u}$, respectively, as a form of regularization to avoid spurious numerical instabilities. We invoke the constraints of equation (2) to impose the rake of fault slip, while letting nontectonic parameters unbounded. We solve this system using a Sequential Least Squares algorithm.

[17] The data vector is a combination of the GPS horizontal velocity components $\mathbf{d}^{\mathrm{GPS}}$ and the InSAR LOS measurements $\mathbf{d}^{\mathrm{SAR}}$. When jointly inverting $P$ InSAR stacks and $N$ GPS networks, we add a relevant subscript to the vectors and form the global data vector in series:

$$
\mathbf{d}=\left(\begin{array}{c}
w \mathbf{d}_{1}^{\mathrm{SAR}} \\
\vdots \\
w \mathbf{d}_{P}^{\mathrm{SAR}} \\
\mathbf{d}_{1}^{\mathrm{GPS}} \\
\vdots \\
\mathbf{d}_{N}^{\mathrm{GPS}}
\end{array}\right)
$$


The InSAR data consist typically of a few thousand points, while the GPS vectors, just a few hundreds. To compensate for the difference in the number of point measurements, we introduce a weight $w$ on the InSAR data. The model parameters are then organized as follows:

$$
\mathbf{m}=\left(\begin{array}{c}
\mathbf{s} \\
\mathbf{o}_{1} \\
\vdots \\
\mathbf{o}_{P} \\
\mathbf{r}_{1} \\
\vdots \\
\mathbf{r}_{N}
\end{array}\right)
$$

where $\mathbf{s}$ is a vector of slip rates on fault patches and opening rates of dilatation sources (typically a few hundreds of parameters). The vectors $\mathbf{o}_{i}$ are three orbital parameters for InSAR stack $i$ and each $\mathbf{r}_{i}$ contains two reference frame parameters for GPS network $i$. Data and model space are connected through the design matrix:

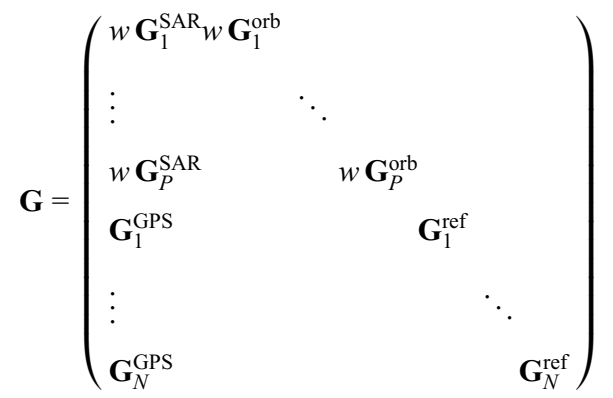

where the weight $w$ on InSAR data is taken into account. The $\mathbf{G}^{\mathrm{SAR}}$ and $\mathbf{G}^{\mathrm{GPS}}$ matrices are computed using unitary slip on rectangular fault patches using a combination of strike slip and dip slip prescribed by an assumed rake of the slip vector. We use the semianalytic solution of Wang et al. [2003] for deformation in a layered model. Lateral heterogeneities in the Earth's crust sometimes affect the distribution of slip velocity [e.g., Fay and Humphreys, 2005; Lundgren et al., 2009; Lindsey and Fialko, 2013]. For arbitrarily 3-D elastic media, we use Gamra-Géodynamique Avec Maille Rafinée Adaptivement, a fully numerical method based on adaptive multi grid with embedded faults [Landry et al., 2012]. For those patches that are infinitely long to represent relative plate motion, we use the solution for a two-dimensional buried screw dislocation:

$$
u=\frac{1}{\pi} \arctan \left(\frac{y}{D}\right),
$$

where $u$ is the surface fault parallel displacement, $y$ is the fault-perpendicular coordinate, and $D$ is the locking depth or the solution of Segall [2010] for a layered medium

$$
u=\frac{2}{\pi} \frac{\gamma}{1+\gamma}\left[\arctan \frac{y}{D}+\sum_{m=1}^{\infty}\left(\frac{1-\gamma}{1+\gamma}\right)^{m} \arctan \frac{y}{D+2 H m}\right] \text {, }
$$

where $H$ is the bottom depth of the top layer and $\gamma=$ $\mu_{\text {top }} / \mu_{\text {down }}$ is the rigidity ratio. Here we ignore the visco- elastic effects of historical earthquakes [e.g., Johnson and Segall, 2004]. Also, the deep-seated deformation accommodated by both localized fault slip and more distributed strain are modeled using elastic dislocation [Fay and Humphreys, 2005; Lundgren et al., 2009].

[18] The smoothing between slip patches is obtained through a finite difference approximation $\mathbf{L}$ of the Laplacian operator for irregular surfaces [Huiskamp, 1991; Kositsky and Avouac, 2010]. Fault estate is separated into $K$ segments that are smoothed independently of each other so we form the smoothing operator $\mathbf{D}$ as follows:

$$
\mathbf{D}=\Lambda\left(\begin{array}{lll}
\mathbf{L}_{1} & & \\
& & \\
& \ddots & \\
& & \mathbf{L}_{K}
\end{array}\right)
$$

The strength of smoothing $\boldsymbol{\Lambda}$ is determined based on the resolution of fault patches. Using a singular value decomposition, we first determine the resolution matrix of the inversion:

$$
\mathbf{R}=\mathbf{G}^{\dagger} \mathbf{G}
$$

where $\mathbf{G}^{\dagger}$ is the generalized inverse of the forward operator obtained by truncated singular value decomposition as a form of Tikhonov regularization [e.g., Pritchard et al., 2002; Aster et al., 2012]. The eigenspectrum is truncated at eigenvalues lower than a threshold defined as the ratio of the expected noise to the expected fault velocity (equation (15)). Then, the smoothing weight is determined from the following equation:

$$
\Lambda_{i i}=\lambda_{1}+\lambda_{0} \cos \left(\frac{\pi R_{i i}}{2}\right)^{10}
$$

where the coefficients $\lambda_{1}$ and $\lambda_{0}+\lambda_{1}$ are obtained empirically and correspond to the smoothing weights for well and poorly resolved parameters, respectively. The high exponent is chosen so as to obtain a sharp decrease in smoothing for parameters with resolution greater than one half.

\subsection{The Case for GPS Baseline Velocity and InSAR Velocity Gradients Inversions}

[19] We now consider the inversion of the baseline velocity between pairs of GPS stations and of the horizontal gradient of the LOS data. For sufficiently small GPS networks, it is often sufficient to assume a constant vector to represent the velocity of the reference frame, but for larger networks, a radial velocity and an Euler pole are a more adequate representation. However, simultaneously inverting for these two parameters is not a linear inversion, which complicates the analysis of large networks. It seems therefore advantageous to use the relative velocity between pairs of nearby stations as data constraints. In general, taking the difference between two time series of displacement increases the noise by a factor of $\sqrt{2}$. But fortunately, as a strong component of the noise in GPS time series is spatially correlated [Dong et al., 2006; Williams et al., 2004; Langbein, 2008; Hill et al., 2009], time series of baseline displacements have a much reduced noise, here by a factor of $\sim 2.5$ (Figure 3 ). 

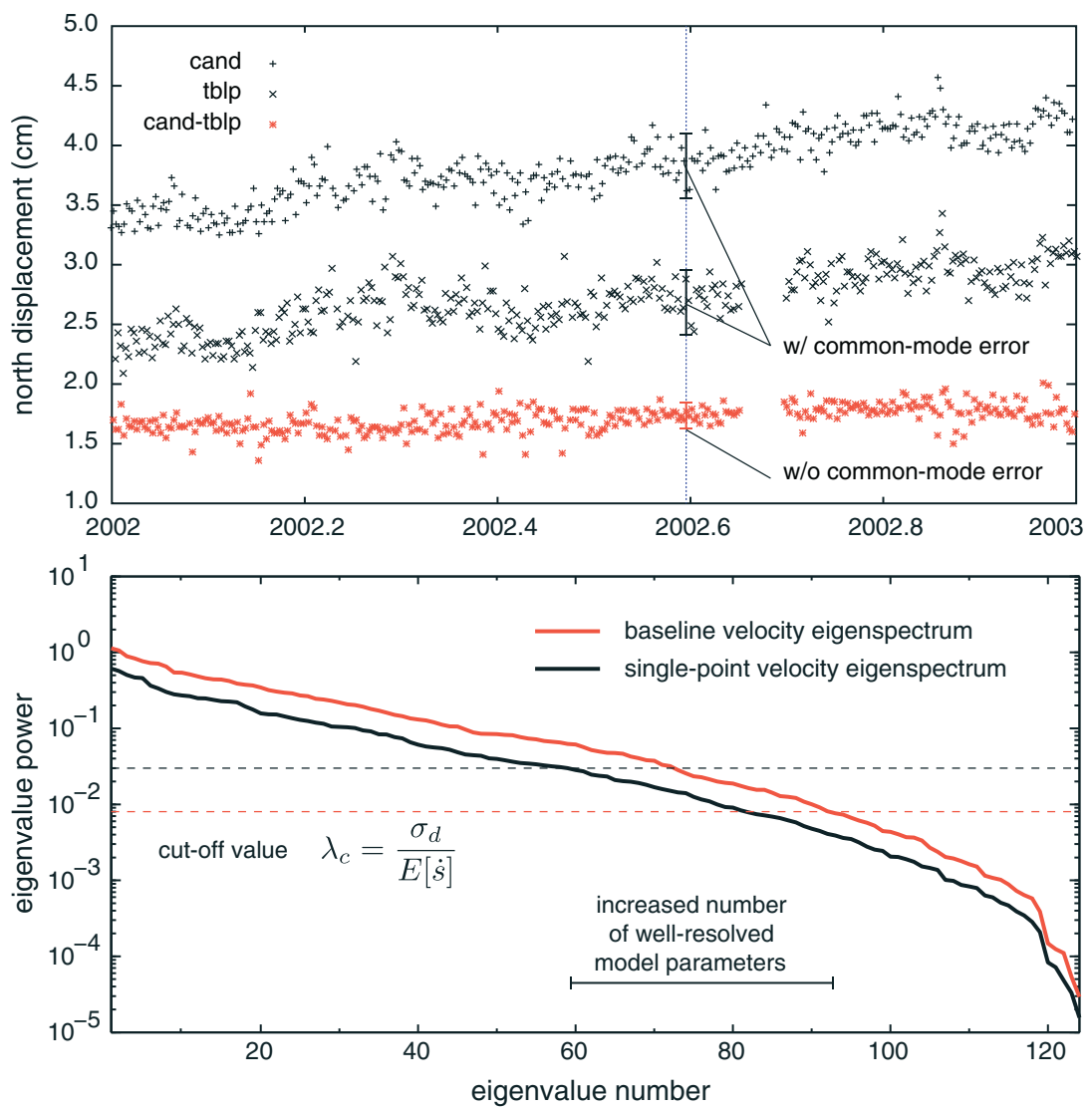

Figure 3. Merits of GPS baseline inversions. (top) Raw time series of GPS stations CAND and TBLP, $10 \mathrm{~km}$ apart, and their difference. A coherent noise is removed in the differencing process, and the noise level of the baseline time series is smaller than the noise in individual time series. (bottom) The eigenspectrum of the Green's function matrix of GPS velocity and GPS baseline velocity. The eigenvalues of the baseline velocity are approximately $\sqrt{2}$ higher than the ones for the velocity, and the noise is reduced by at least a factor of 2 , leading in this case to about 30 more well-resolved parameters.

[20] To determine the baseline velocities and the LOS gradient, we operate as follows. First, we perform Delaunay triangulation of the point coordinates and identify the unique edges forming the triangular mesh. For GPS, each point is a GPS station; for InSAR, each point is a coherent reflector. Then, we discard those pairs separated by less than $500 \mathrm{~m}$ or by more than $50 \mathrm{~km}$. The difference between the velocities of two connected points forms the basis of the data vector $\mathbf{d}$ in our inversion. Because the velocity of the reference frame does not contribute to the baseline velocities, the model parameters reduce to

$$
\mathbf{m}=\left(\begin{array}{c}
\mathbf{s} \\
\overline{\mathbf{o}}_{1} \\
\vdots \\
\overline{\mathbf{o}}_{P}
\end{array}\right)
$$

where the relative range of the LOS is absent of the orbit parameters $\overline{\mathbf{o}}_{i}$. The forward model of fault slip and dilatation opening corresponds to the difference between predicted displacements at each end of the connecting edge and is marked by an upper bar symbol ( ). The design matrix is written

$$
\mathbf{G}=\left(\begin{array}{llll}
w & \overline{\mathbf{G}}_{1}^{\mathrm{SAR}} w \overline{\mathbf{G}}_{1}^{\mathrm{orb}} & & \\
\vdots & & \ddots & \\
w \overline{\mathbf{G}}_{P}^{\mathrm{SAR}} & & & w \overline{\mathbf{G}}_{P}^{\mathrm{orb}} \\
\overline{\mathbf{G}}_{1}^{\mathrm{GPS}} & & \\
\vdots & & & \\
\overline{\mathbf{G}}_{N}^{\mathrm{GPS}} & & &
\end{array}\right)
$$

An effect of using baseline data is to increase the number of lines in $\mathbf{G}$ by a factor of 2 to 3 . The rest of the inversion procedure, such as the definition of $\mathbf{A}, \mathbf{D}, \mathbf{H}$, and $\mathbf{h}$, is the same as explained in section 3.1.

[21] The eigenvalues of the design matrix (14) is increased by a factor of about $\sqrt{2}$ on average compared to the ones obtained with definition (7) (Figure 3). The increase in sensitivity of the design matrix could compensate an increase of the noise of the relative velocity. But because the latter decreases, the result is an improved robustness of the inversion to data noise and an increased resolution of model 

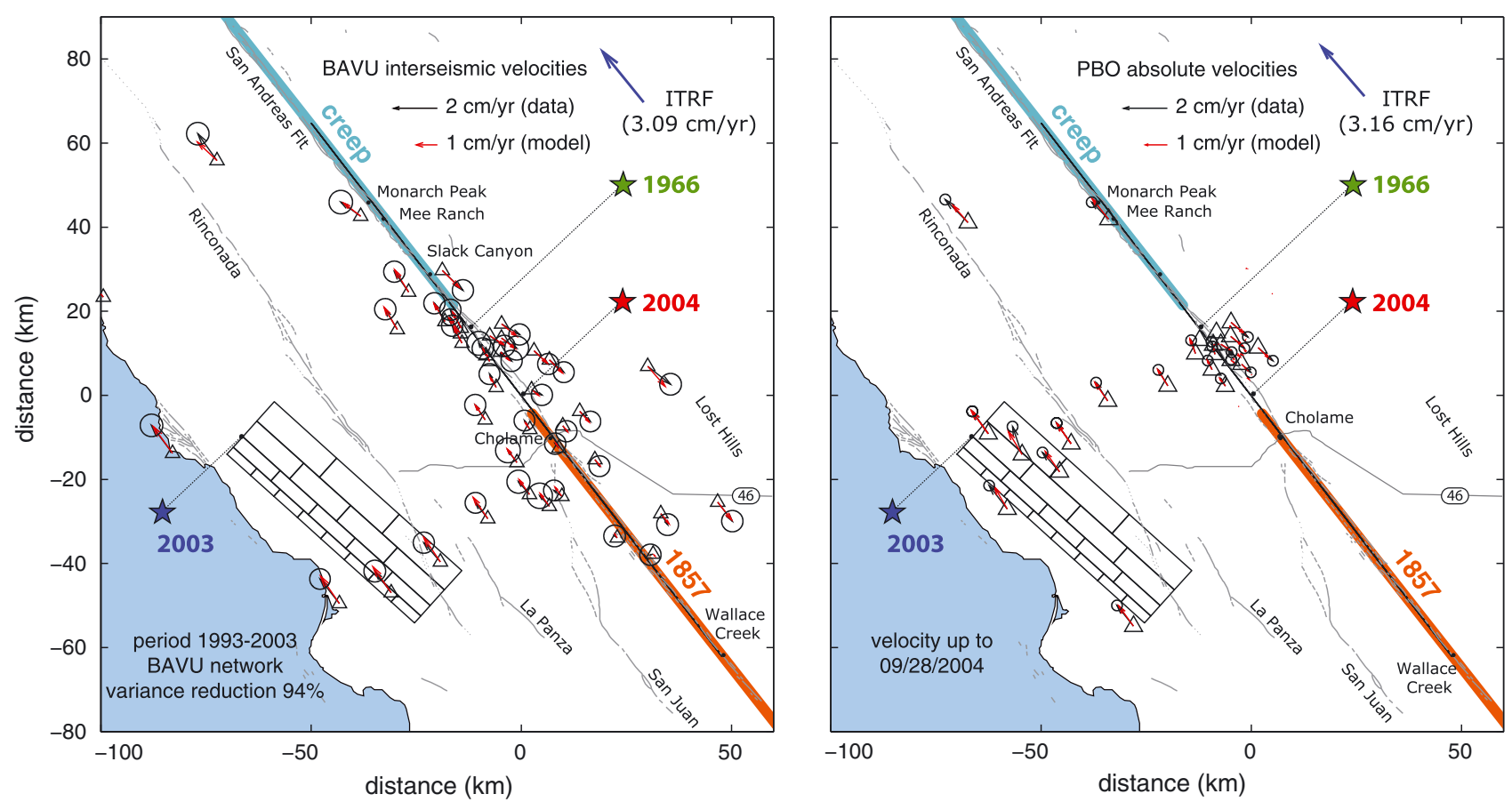

Figure 4. (a) Pre-earthquake velocity field and forward model at the Bay Area Velocity Unification (BAVU) network [d'Alessio et al., 2005]. The velocity is relative to the SAF and the residual International Terrestrial Reference Frame (ITRF) velocity is shown for reference. Baseline velocity, forward model, and residuals are shown in Figure S3. (b) Velocity field and forward model at the EarthScope Plate Boundary Observatory (PBO) network. Baseline velocity, forward model, and residuals are shown in Figure S2.

parameters. The number of well-resolved model parameters can be estimated from the eigenspectrum of the design matrix using the cut-off eigenvalue:

$$
\lambda_{c}=\frac{\sigma_{d}}{E[\dot{s}]}
$$

where $\sigma_{d}$ is a characteristic noise level of the data and $E[\dot{s}]=30 \mathrm{~mm} / \mathrm{yr}$ is the expected value of fault slip velocity. Using $\sigma_{d}=1 \mathrm{~mm} / \mathrm{yr}$ for velocity, which is typical for horizontal velocity vectors of decade-long continuous GPS time series, and $\sigma_{d}=0.4 \mathrm{~mm} / \mathrm{yr}$ for baseline velocity, which is a factor of 2.5 smaller, we find that inversion using baseline velocity can resolve about 30 more model parameters than the one using point-wise velocity within their respective noise level (Figure 3 ). In addition, two model parameters per GPS network and one for each InSAR image are removed from the model space. As the inversion of baseline velocity offers significant improvements over the inversion of absolute velocity, we will only present results from the former method. For illustration purposes, we present both the fit to the baseline and absolute velocities. In the later case, the best fitting velocity of the reference frame is estimated in a post processing step.

\subsection{Bootstrap Uncertainty Estimation}

[22] To describe the sensitivity of the model parameters to data noise, we use a bootstrap technique where we perturb the data used in the inversion with a random Gaussian noise. After generating and inverting $N$ modified data sets, we can describe the statistics of a large population of best fitting models. In the following, we use $N=100$. This method allows us to describe the model uncertainties including the effect of smoothing, nonnegativity constraints, and data coverage that are not included in other analytic estimates. For example, if redundancy is large in the data, model parameters may not be largely affected by data noise or potential outliers. To identify the expected amplitude of noise on a data set basis, we estimate the data variance based on the residuals of our best fitting model.

\section{Interseismic Creep Before the $2004 M_{w} 6$ Parkfield Earthquake}

[23] To estimate fault slip rates before the $2004 M_{w} 6$ Parkfield earthquake, we combine GPS data from the Bay Area Velocity Unification (BAVU) [d'Alessio et al., 2005] (Figure 4a) and Plate Boundary Observatory (PBO) networks (PBO compilation pbo.final snfol.vel released in August 2011 and available at ftp://data-out.unavco.org, Figure $4 \mathrm{~b})$. We select the stations located within in a rectangular domain between point coordinates $(-100,-80)$ and $(70,60)$ expressed in kilometers relative to the reference coordinates (W120.3740, N35.8150). We complement these observations with the interferogram stacks described in section 2, using ascending and descending Envisat acquisitions (Figure 5). Before inverting, we subsample InSAR data every $1 \mathrm{~km}$ and discard areas deemed biased by noise or nontectonic signals. We use a cut-off value of the noise estimate when available, but we also reject some areas by visual inspection.

[24] The surface displacements are assumed to be the result of slip on faults. We also include a dilatation source 

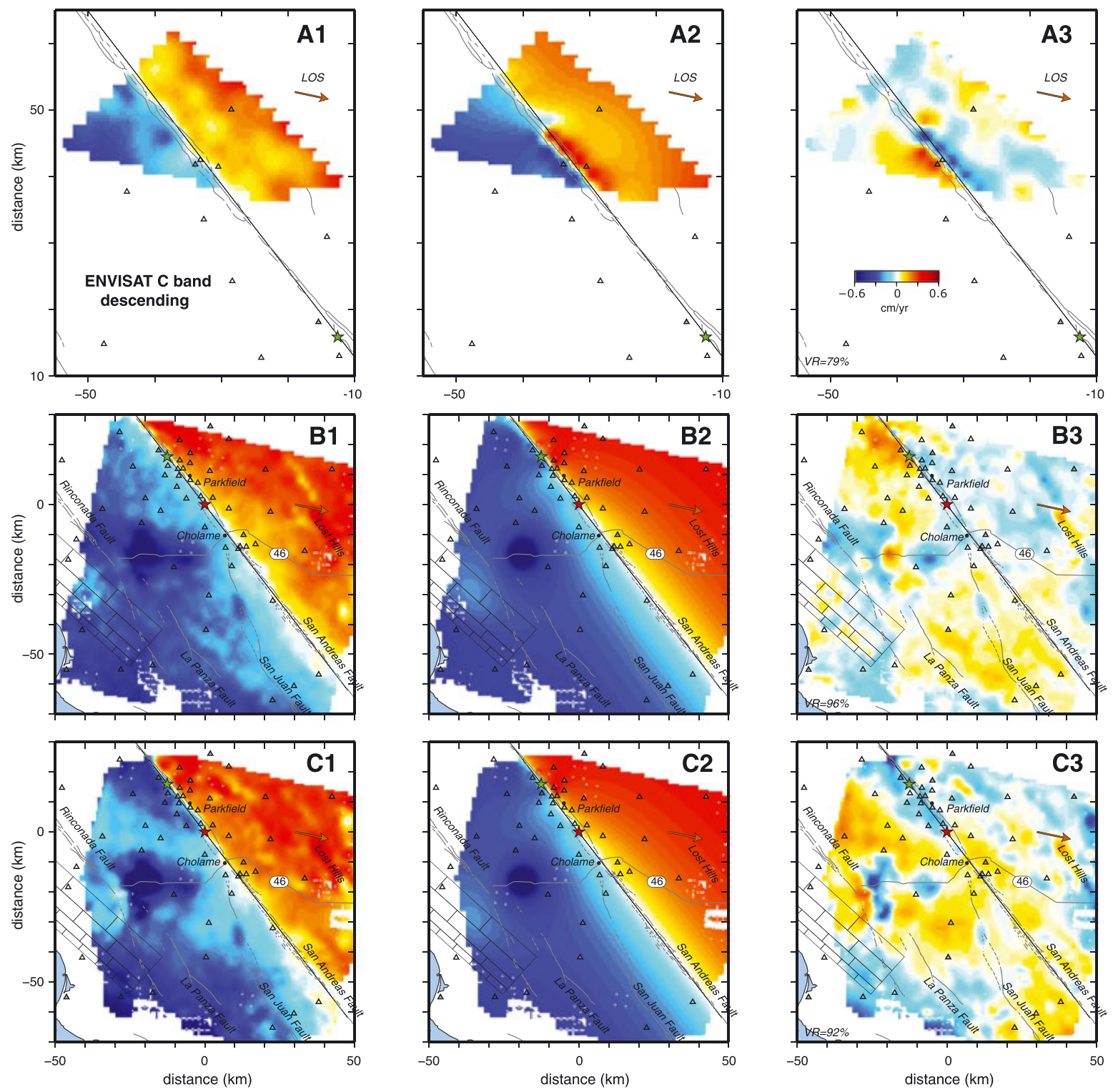

Figure 5. (1) InSAR average velocity, (2) forward model, and (3) residuals for the period 1992-2004, for (a) ERS data (see baseline plot in Figure 2), (b) Envisat data processed by De Michele et al. [2011], and (c) same raw data as Figures $5 \mathrm{~b} 1-5 \mathrm{~b} 3$ but processed with MInTS.

below Paso Robles to account for reservoir extraction in this area. We consider five fault segments, which are discretized and smoothed independently of each other. They are the San Simeon, Cholame, Parkfield, and creeping segments, complemented by the root of the SAF, which consists of seven large patches and one infinitely long fault with a locking depth of $D=13 \mathrm{~km}$. Because slip is allowed at shallower depth, this implies that the locking depth is $13 \mathrm{~km}$ or less.

[25] With the Cholame, Parkfield, and creeping segments, we represent a stretch of the SAF going from Wallace Creek to the south, to $20 \mathrm{~km}$ north of Monarch Peak, in the middle of the creeping segment. In a preliminary study, we tested the necessity of allowing creep on the La Panza, Rinconada, and Lost Hills faults. Among these, we found that only shallow creep were occurring on the Lost Hill Fault and that ignoring this effect had little impact on the inversion results elsewhere.

[26] We discretize the fault segments into rectangular patches of varying size, with length and width increasing with depth. The patch sizes on the San Simeon, Cholame, and creeping segments are chosen manually so as to obtain a resolution above a critical value of 0.5 (Figure S5). At Parkfield, we prefer to sample the fault more finely, so as to obtain a better spatial resolution. The geometry of the San Simeon segment is inspired from the work of Johanson and Bürgmann [2010] and guided by seismicity and constraints from geodesy. With the chosen discretization, the resolution is above 0.8 and 0.7 in the Cholame and creeping segments, respectively. Resolution is close to one in the top $4 \mathrm{~km}$ at Parkfield but rapidly decreases at greater depth. 


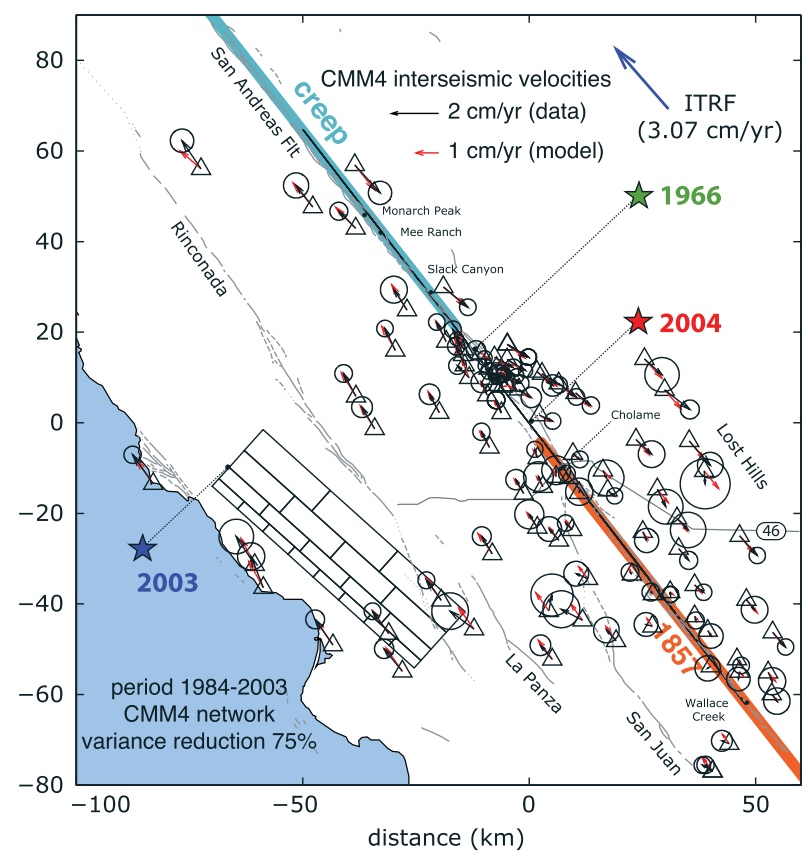

Figure 6. Pre-earthquake GPS velocity field and forward model at the SCEC Crustal Motion Map 4 (CMM4) compilation network [Shen et al., 2011]. Baseline velocity, forward model, and residuals are shown in Figure S4.

The San Simeon segment is a dipping fault and with the chosen sampling this gives rise to a much increased resolution, compared to neighboring vertically dipping segments (Figure S6).

[27] We invert for fault slip, dilatation opening, and other nontectonic parameters using the method described in section 3.2, using the relative velocity between pairs of GPS stations and the gradient of InSAR data. We set an upper bound of slip velocity of $50 \mathrm{~mm} / \mathrm{yr}$. The results vary depending mostly on our choice of the weight $w$ put on InSAR and the choice of the underlying rigidity structure. Within a reasonable range, the weight of smoothing influences little the results because patches are overall large and well resolved. We therefore chose a nominally small value to control the intensity of smoothing.

[28] Our preferred models use a weight on InSAR data of $w=0.3$ and either a layered elastic structure with a depth dependence of elastic moduli prescribed by the preliminary reference Earth model [Dziewoński and Anderson, 1981] or a 3-D elastic distribution described by the SCEC Community Velocity Model - Harvard (CVM-H version 11.9.1) [Tape et al., 2009]. Both elastic structures give rise to similar models, with GPS data reduced by $94 \%$ and a variance reduction for InSAR between 79 and 96\%. The particular choice of weight on InSAR data gives consistent values of deep interseismic slip in the two periods of observation considered, while larger weights increase the deep velocity unreasonably. The fit to the GPS velocity of the BAVU network is shown in Figure 4a. The forward model explains the data well and there is no systematic patterns in the residuals. The fit to the PBO velocity is shown in Figure $4 \mathrm{~b}$. The same model explains these data well. The horizontal velocity of the ITRF reference frame is a byproduct of our inversion and we find that the $\mathrm{PBO}$ and BAVU solutions share the same reference frame within $0.7 \mathrm{~mm} / \mathrm{yr}$. The observed, modeled, and residual baseline velocities are shown in Figures S3 and S2, for the BAVU and PBO networks, respectively. The residuals in the near field are larger and result probably from local effects (crustal structure, topography, damage zone, and/or parallel fault strands) or from variations of fault slip at finer scales than allowed in the inversion.

[29] The fit to the InSAR data is shown in Figure 5. For simplicity, we show the absolute velocity and the LOS displacements (as opposed to the gradients). As the orbital error is estimated in the inversion, we remove it from the data for illustration purposes. The large wavelength of the measurements is in general well explained, but every interferogram stack shows a pattern of irregular residuals. All of them show residual LOS velocity near the SAF. When comparing the same data processed by De Michele et al. [2011] and with MInTS, the residuals show an opposite polarity. This gives us some confidence that some of these residuals are due to atmospheric noise, which is not completely eliminated from the time series processing. The northern interferogram also show near-field residuals. These can be due to tropospheric noise or local effects and, as only a few GPS stations are present at this location, it is challenging to assess the origin of this misfit. It is possible that more shallow fault complexity than is included in our model may be required to explain the data in the near field, including push-up ridges, small fault step overs, and bifurcations that can result in fault-perpendicular motion. As GPS and InSAR absolute velocities are not directly included in the inversion, it is remarkable that they can be explained well by a modeled only tuned to the gradient of the deformation.

[30] The $2003 M_{w} 6.5$ San Simeon earthquake ruptured in the period of observation and was captured by 4 out of the 89 interferograms used in the stack. The San Simeon coseismic deformation is largely averaged out in the stacking procedure, but its effect is likely to create an apparent creep on the San Simeon segment (Figure 7 and S6). Based on this result alone, we cannot conclude that the San Simeon is ongoing steady creep rates in the 1992-2003 period.

[31] The inferred creep rate along the SAF can be decomposed based on overall behavior into three segments (Figures 7 and S6). The Cholame segment, to the south, appears locked from its southernmost extension in the model to north of the 2004 Parkfield epicenter. This result is consistent with previous findings [Harris and Segall, 1987; Segall and Harris, 1987; Segall and Du, 1993; Bakun et al., 2005], where no southern termination of the Parkfield locked zone was clearly identified. In the Cholame segment, the depth of the locked zone is poorly resolved and may be deeper. But at least the first $13 \mathrm{~km}$ of the fault seem unambiguously locked. The Parkfield segment shows a complex pattern of creep and locked regions. A patchy distribution of shallow creep shows some correlation with seismicity. And in general little slip occurs in the middle of the seismic streaks identified by Waldhauser et al. [2004]. Some creep occurs below the bottom seismic streak suggesting that microseismicity at Parkfield marks a transition in fault behavior [Barbot et al., 2012]. Slip rates increase to the north of the 1966 epicenter to transition to the creeping segment. Surface creep at Parkfield is patchy, with isolated regions of fault motion. To the north, the creeping segment exhibit more 

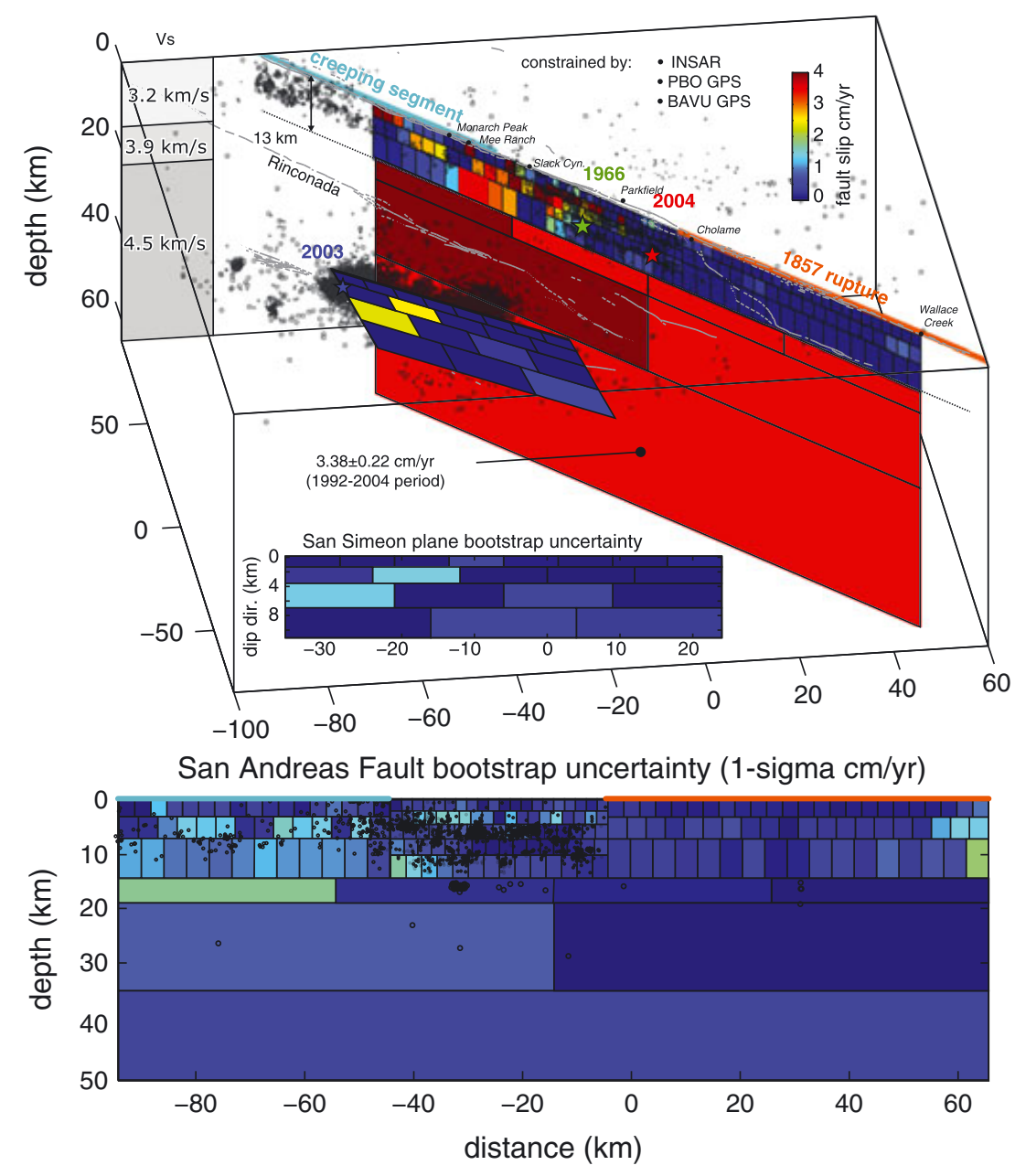

Figure 7. Spatial distribution of interseismic fault creep in the 1999-2004 period from the joint inversion of GPS and InSAR data. The $1 \sigma$ uncertainty from bootstrap analysis indicates large uncertainties in the creeping segment. The green, red, and purple stars represent the hypocenters of the 1966 and 2004 $M_{w} 6.0$ Parkfield and of the 2003 San Simeon earthquakes, respectively.

widespread creep, but the velocity is not uniform, with some isolated areas appearing locked. The sliding rate between the North American and the Pacific plates are inferred to be $33.8 \pm 2.2 \mathrm{~mm} / \mathrm{yr}$ across the $\mathrm{SAF}$, with a slight increase below the creeping segment.

[32] It is informative to consider the uncertainty on fault slip rates based on the bootstrap method described in section 3.3 (Figure 7). These uncertainties reflect potential biases caused by data noise or insufficient data coverage on the inversion and include the effect of the regularization and positivity constraints that may not be accounted for by other estimates. The uncertainty is larger at the edge of the domain covered by data, as expected. But at other locations, the Cholame segment exhibits an overall low uncertainty. In the Parkfield segment, uncertainties are large at depth, to the north and at shallow depth. This indicates that data noise can affect the estimation of shallow creep and that it may be more widespread than inferred in the best fitting model. The region surrounded by seismic streaks does not suffer from large uncertainties, so the best fitting model seems robust at this location. The creeping segment suffers from large uncer- tainties, due mostly to insufficient redundancy in the surface coverage, which leads to the possibility of outliers biasing the results. However, the apparent locked region between Mee Ranch and Monarch Peak does not seem to be much influenced by data noise and the estimated slip rates there seem robust. The uncertainties on the San Simeon segment are the greatest where the highest slip rates take place but smaller than half the estimated rates, so the results seem to hold at this location.

[33] Inference of deep interseismic velocity from GPS and InSAR data can be subjected to bias from modeling assumptions. For example, comparing with inversions assuming a homogeneous structure, we notice that ignoring the depth dependence of rigidity leads to a systematic reduction of the deep velocity by about $2 \mathrm{~mm} / \mathrm{yr}$. We do not find systematic differences between the slip models that assume layered elastic properties and the ones obtained with the CVM-H tomography structure. This is probably due to the fact that interseismic slip occurs mostly at depth, where 3 -D variations are either smaller or less well imaged. Relative weight of InSAR versus GPS data in the inversion influences the 
inferred deep velocity more. Inversions with InSAR weight $w=1$ to 10 give rise to estimates of deep velocity from 28.8 to $18.1 \mathrm{~mm} / \mathrm{yr}$ and systematically worsen the fit to GPS. This indicates that InSAR overall favors slower deep interseismic velocity than GPS. Our preferred value of $w=0.3$ gives rise to a deep velocity of $33.8 \mathrm{~mm} / \mathrm{yr}$, in better agreement with the geological slip rates of Toké et al. [2011] and Sieh and Jahns [1984].

[34] To explore the variability of fault slip further back in time, we repeat our inversion using the large compilation of surface velocity from campaign GPS surveys compiled in SCEC Crustal Motion Map 4 (CMM4) compiled by Shen et al. [2011] and that started as early as 1986, which is 20 years after the $1966 M_{w} 6$ Parkfield earthquake. We find that all the CMM4 data can be explained by a very similar model of fault slip (Figures 6 and S4). This result indicates that the strong coupling from the Cholame to far north into the Parkfield segment was persistent for at least 20 years before 2004, compatible with the results of previous studies [Harris and Segall, 1987; Murray et al., 2001; Bakun et al., 2005; Murray and Langbein, 2006].

\section{Interseismic Creep After the $2004 M_{w} 6$ Parkfield Earthquake}

[35] The postseismic transient following the $2004 M_{w} 6$ Parkfield earthquake is characterized by rapid afterslip, with a relaxation time scale of about 3 months, and a slower lower-crustal relaxation with a time scale of 1 year [Johanson et al., 2006; Barbot et al., 2009; Bruhat et al., 2011]. To avoid the contamination of a strong postseismic transient, we look at geodetic data 2 years after the 2004 event. Although there is a continuum between postseismic and interseismic deformation, we focus our attention on this period where the deceleration of surface displacements is less obvious and can be considered the early interseismic stage. In the 2006-2012 period, the PBO network has been greatly augmented compared to its pre-2004 version, consisting of about 80 permanent stations in the domain considered (Figure 8). The PBO network offers near- and far-field stations, which can place better constraints on the plate convergence rate. The available InSAR catalog offers a complete coverage with multiple look angles of the SAF trace in our domain of interest (Figure 1). However, in the time period considered, less independent interferograms are available (Table 1) and we can expect more contamination by tropospheric noise. Furthermore, the look direction of ascending orbits is almost perpendicular to the SAF so the Envisat descending stack is the most sensitive to SAF displacements. We discard ALOS LOS data northeast of Coalinga, Lost Hills and the five freeway due to the agricultural activity in Central Valley that reduces coherence and increases nontectonics signals. Some data in all stacks are also ignored based on a threshold on an estimate of the signal-to-noise ratio obtained from MInTS. The increased coverage allows us to sample the creeping segment more finely while keeping a high inversion resolution (Figure S8).

[36] We simultaneously invert the PBO average velocity field in the 2006-2012 period (Figure 8) and data from four InSAR tracks (Figure 9). We use the same inversion parameters as for the 1992-2004 period, including smoothing

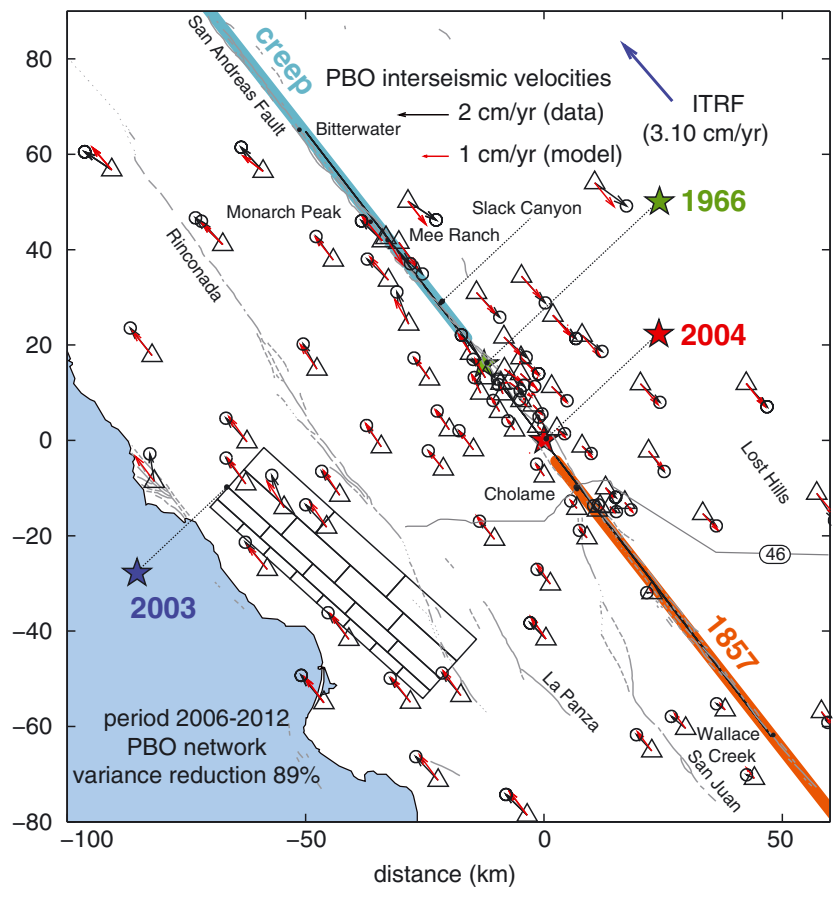

Figure 8. Velocity fields and forward model at the PBO network in the 2006-2012 period. The velocity is relative to the SAF and the residual ITRF velocity is shown for reference. Baseline velocity, forward model, and residuals are shown in Figure S7.

strength, relative InSAR weight, and the rigidity structure. The GPS baseline velocity is reduced by $89 \%$. The largest residuals for the absolute velocity occur in the far field of the SAF, close to the San Simeon segment or near the boundary of our domain of observation. The most apparent misfit is in the SAF fault-perpendicular direction, probably due to edge effects, i.e., the fact that we ignore the deformation in the northern creeping segment, which affects some stations in our domain of interest. The fit to the GPS near-field station is good, with no obvious patterns in the residuals.

[37] The InSAR gradient data are reduced by $45 \%$ to $79 \%$ in the ascending direction and by $82 \%$ in the descending direction (Figure 9), consistent with sensitivity of ascending and descending orbits to strike slip on the SAF. While some tectonic signal may be better explained using a smaller fault discretization, we attribute most of the unexplained signal to residual tropospheric noise, particularly for the ascending tracks. The large wavelength signal is well reproduced by the model, but some scattered residuals appear for all tracks. The ascending Envisat and ALOS data can be most easily compared as their horizontal look direction is similar (yet Envisat is more sensitive to vertical deformation). The large ALOS residuals that correlate with the SAF cannot be found in the ascending Envisat residuals. Some residuals localize near the SAF in the Envisat descending track, but as similar patterns can be sometimes found in the ALOS data but not in other data sets, it is likely that some residuals may be due to troposphere correlated with topography. There are large residuals in the Cholame segment in the ALOS data. These patterns do not change polarity across the fault and may not be of tectonic origin. 

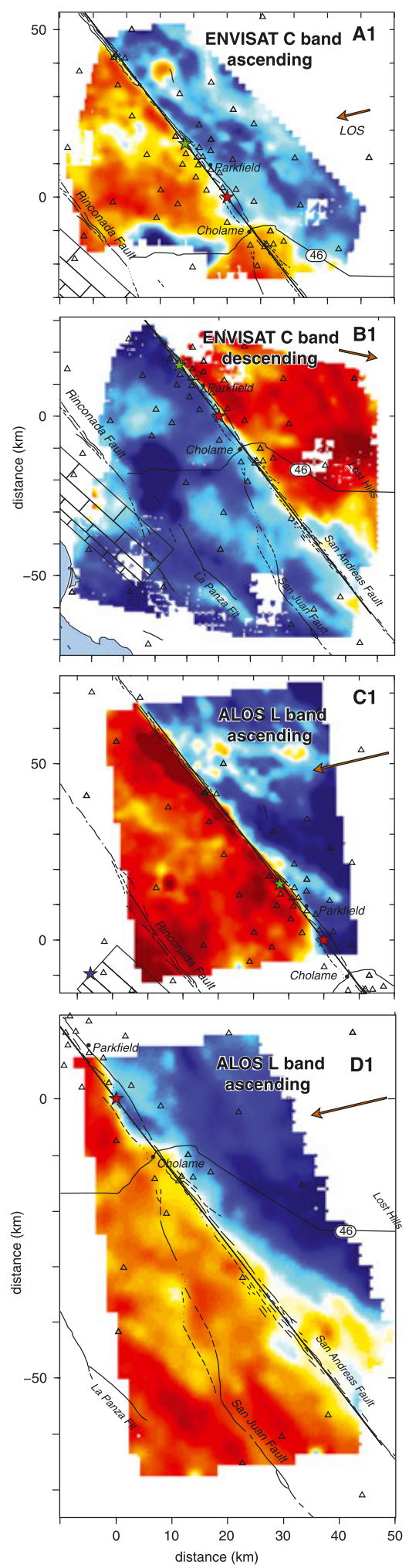
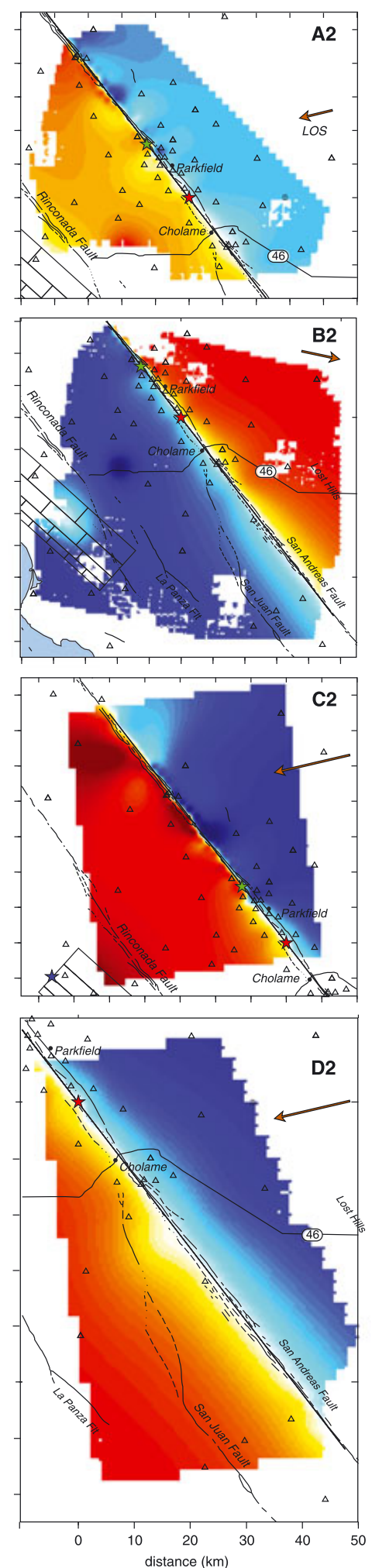
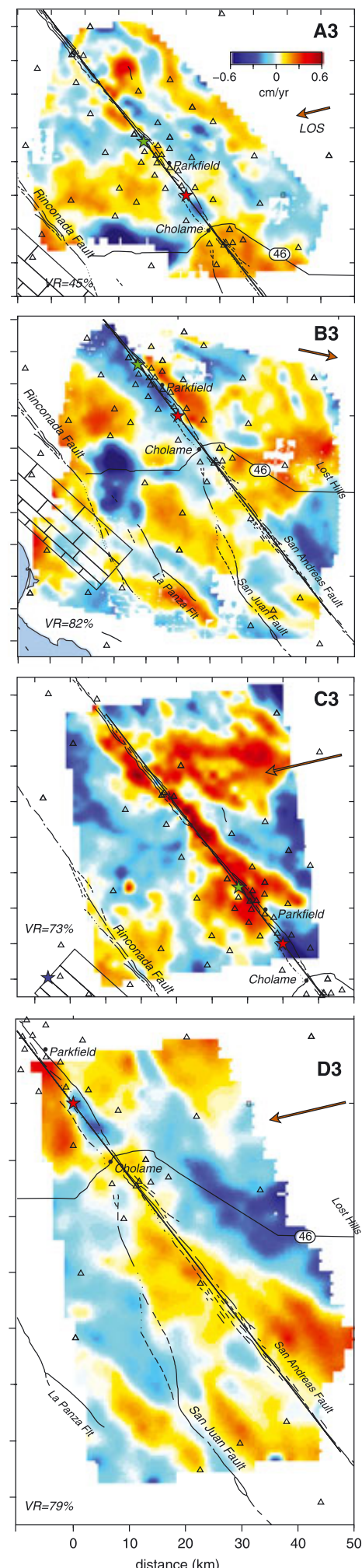

Figure 9. (1) InSAR average velocity, (2) forward model, and (3) residuals for the period 2006-2012, for $(a, b)$ Envisat data and (c,d) ALOS data. All processed with MInTS. 

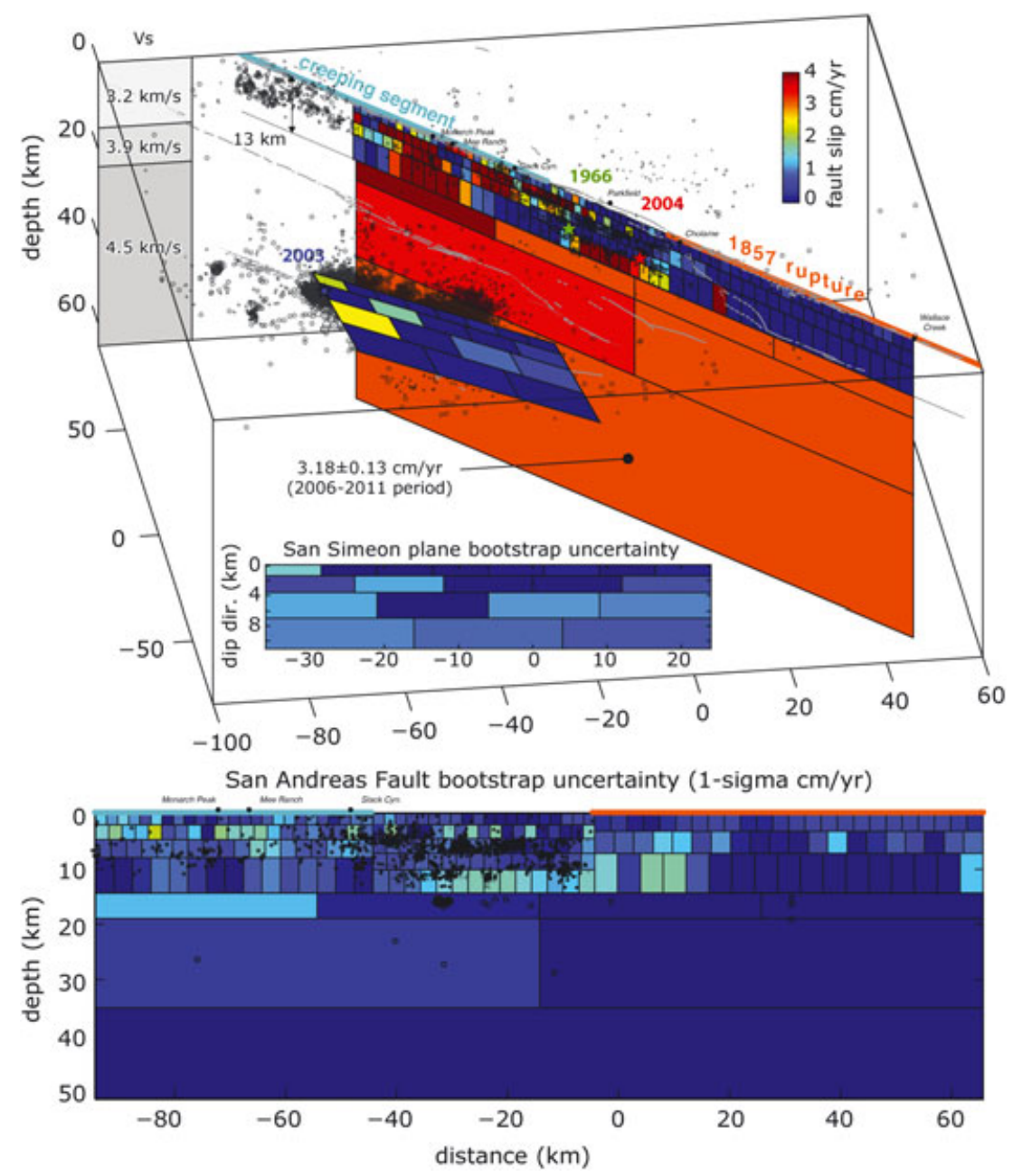

Figure 10. Spatial distribution of interseismic fault creep in the 2006-2012 period from the joint inversion of GPS and InSAR data. The $1 \sigma$ uncertainty from bootstrap analysis indicates larger uncertainties at the bottom of the Parkfield segment. The green and red stars represent the hypocenters of the 1966 and $2004 M_{w} 6.0$ Parkfield earthquakes.

[38] The pattern of interseismic slip rate in the 2006-2012 period is shown in Figures 10 and S9. The Cholame segment seems locked from its southern extension to $8 \mathrm{~km}$ south of Cholame. A deep locked segment appear at the northern extension, next to the Parkfield segment, but the uncertainties from the bootstrap analysis indicate that some creep may in fact occur there. Bootstrap analysis also indicates the possibility of creep below Wallace Creek, but these uncertainties are due to side effects as data coverage is sparser at the boundary of the domain of interest.

[39] In the Parkfield segment, deep creep takes place below the bottom seismic streak but not in the region surrounded by microseismicity. The bootstrap analysis indicates that little slip occurs there, regardless of reasonable noise added to the data before inverting, so this result seems robust and least affected by data noise. Some shallow creep also takes place in the top $4 \mathrm{~km}$ layer, particularly to the north, at the beginning of the creeping section, where it correlates with microseismicity.

[40] In the creeping segment, the velocity seems larger than plate rate, which is indicative of transient behavior.
Some areas, for example, below Monarch Peak or Slack Canyon appear locked, but the bootstrap analysis indicates that some slip may occur there. Considering the best fitting inversion and the bootstrap analysis together, the transition between the Parkfield and creeping segments seem marked by an area of reduced slip rates below $6 \mathrm{~km}$ depth. As this region did not produce large earthquakes in recorded history, it likely experiences cycles of accelerated and reduced aseismic slip. Overall, the slip rates on the creeping segment are not uniform, compatible with the results of Rolandone et al. [2008] obtained with GPS data alone and those of [Ryder and Bürgmann, 2008] obtained from InSAR analysis.

[41] Some creep appears to occur on the San Simeon segment, concentrating in the same area that moves in the pre-2004 period. These results are subject to much variability, given the bootstrap uncertainty, and are supported only by some GPS stations and the Envisat descending data, so they should be interpreted with caution.

[42] The inferred convergence rate between the North American and Pacific plates in the 2006-2011 period is 
$31.8 \pm 1.3 \mathrm{~mm} / \mathrm{yr}$, which agrees with the results for the pre-2004 period within the error bounds.

\section{Discussion}

[43] The distribution of velocity across the SAF shows notable differences at key different periods of the earthquake cycle. These differences may shed light on important questions regarding the mechanics of earthquake generation in the region. In particular the kinematics may inform how earthquakes in the Parkfield region interact with neighboring segments and how the segmentation of the SAF into different segments operates over time. We discuss some implications below.

\subsection{The Evolution of Apparent Coupling at the Transition Between the Cholame and Parkfield Segments: A Southern Termination of the Parkfield Seismogenic Zone?}

[44] The seismic behavior of the Parkfield segment was under much scrutiny to understand the kinematics of the recurrence of $M_{w} 6$ events. Using geodetic [Harris and Segall, 1987; Segall and Harris, 1987; Segall and Du, 1993; Murray et al., 2001; Bakun et al., 2005; Murray and Segall, 2005; Murray and Langbein, 2006; Barbot et al., 2009; Bennington et al., 2011] or seismological [Niu et al., 2003; Custódio et al., 2005; Uchide et al., 2009; Ziv, 2012] data, many aspects of the interseismic, coseismic, and postseismic deformation have been documented. In particular, there is a possibility that the streaks of microseismicity described by Waldhauser et al. [2004] and Thurber et al. [2006] represent the boundary of the seismogenic zone at Parkfield [Barbot et al., 2012].

[45] Recently, Barbot et al. [2012] presented a physical model of the earthquake cycle based on rate-and-state friction that explains the many seismological and geodetic observations, including some variability of recurrence times of $M_{w} 6$ earthquakes and the change of hypocenter location between 1966 to 2004. To explain the nucleation of earthquakes near the 2004 hypocenter and the termination of previous ones to the south, the model assumes a termination of the seismogenic zone a few kilometers south of the 2004 hypocenter. Previous models of fault coupling based on geodetic data [Harris and Segall, 1987; Segall and Harris, 1987; Murray et al., 2001; Bakun et al., 2005; Murray and Langbein, 2006] do not indicate a clear boundary between the Parkfield and Cholame segments, and high coupling is thought to be continuous from Wallace Creek and beyond to the location of the 1966 hypocenter. Our analysis of the geodetic data from 1986 to 2004 and 1992 to 2004 confirms this view. However, the pattern of surface displacements in the 2006-2012 period indicates the presence of a $10 \mathrm{~km}$ long region of low coupling immediately south of the 2004 hypocenter. As our inversion results show similar deep slip rates in the two periods of observation, we are confident that the difference between the two observed behaviors is real and not an artifact of data sampling or noise. There is a possibility that the apparent change of slip rates in the two periods is an artifact caused by a viscoelastic transient relaxation. This is unlikely because the bias introduced by a viscoelastic transient concentrates immediately below the coseismic rupture and not laterally [Bruhat et al., 2011].
[46] We interpret these results as an indication for measurably decelerating creep during the interseismic cycle. This interpretation is broadly compatible with the expected behavior of rate-and-state friction faults, which shows a continuous transition between accelerated postseismic transient and interseismic creep [Rice, 1993; Lapusta et al., 2000; Barbot et al., 2012; Lapusta and Barbot, 2012]. The great 1857 earthquake is thought to have ruptured the SAF from Cajon Pass to Bitterwater, in the creeping segment, breaking through the Parkfield segment [Sieh, 1978a, 1978b; Toppozada et al., 2002]. The implication of this scenario is that the area of low coupling imaged in the 2006-2012 period represents a soft boundary between the Cholame and Parkfield segments: This area would have a combination of frictional properties and confining pressure that is capable of arresting a series of $M_{w} 6$ earthquakes in the Parkfield segment but that would allow larger ruptures to propagate through both segments on occasions. On the contrary, if the 1857 earthquake was in fact preceded by foreshocks in the Parkfield segment a few hours before the rupture [Sieh, 1978a, 1978b; Toppozada et al., 2002], it would mean that the area of low coupling can arrest most events rupturing in the Parkfield segment and that ruptures north and south of this boundary always represent separate seismic events.

\subsection{Microseismicity and the Seismogenic Zone at Parkfield}

[47] The remarkably organized spatiotemporal distribution of microseismicity at Parkfield suggests that clusters of small earthquakes delineate the boundary between areas of different friction properties and in particular surround the seismogenic zone. This interpretation is supported by analysis of seismic data from the 2004 Parkfield earthquake by $M a$ et al. [2008] and Uchide et al. [2009] that show that most of the seismic slip can be confined in the area circumscribed by microseismicity. If slip on the Parkfield segment is controlled by rate- and state-dependent friction [Dieterich, 1979; Ruina, 1983; Rice and Ruina, 1983; Marone, 1998; Rice et al., 2001] and if the seismogenic zone is a large velocity-weakening asperity with a small enough nucleation size surrounded by a velocitystrengthening domain, the areas of the fault that creep during the interseismic and postseismic periods and those that slip seismically should be mostly mutually exclusive, except around the boundaries between velocity-weakening and velocity-strengthening areas [Tse and Rice, 1986; Marone et al., 1991; Lapusta et al., 2000; Lapusta and Liu, 2009; Kaneko et al., 2010]. The velocity distribution in the 20062012 time interval shows a large region of high coupling encircled by microseismicity and completely surrounded by fault estate of presumably velocity-strengthening friction slipping with a higher velocity (Figure 10). This result gives additional credit to the hypothesis that the background seismicity marks the boundary of the seismogenic zone at Parkfield and that the seismogenic zone may be a homogeneous region of velocity-weakening friction.

\subsection{Reasons for Apparent High Coupling at the Cholame/Parkfield Transition Zone}

[48] It may be surprising that the low coupling area south of Parkfield in the 2006-2012 period is not detectable before 2004. It is possible that the surrounding locked areas in 
the Parkfield and Cholame segments affect its behavior by reducing its velocity. If the region was pinned by surrounding locked domains, it could not slip at the same velocity as it would otherwise free of boundaries. Our results indicate that in this context, analyses of surface deformation late in the earthquake cycle may overestimate the area of plate coupling. Another explanation is that there would be significant weakening in afterslip periods followed by marked hardening during the interseismic period (the velocity averaging to plate rate over the period separating seismic events) allowing the creep to be much lower than plate rate late in the interseismic period. This behavior is not expected in simple models of slip evolution based on rate-and-state friction, but a number of potentially important factorsadditional mechanisms of fault weakening such as thermal pressurization and flash heating, heterogeneities in friction, dilatancy effects - may allow significant excursions of slip velocity above and below plate rate [Bilek and Lay, 2002; Toro et al., 2004; Nakatani and Scholz, 2004; Hillers et al., 2006; Noda, 2008; Beeler et al., 2008; Brantut et al., 2008; Rubin, 2008; Sone and Shimamoto, 2009; Fukuyama and Mizoguchi, 2010; Segall et al., 2010; Shibazaki et al., 2011; Faulkner et al., 2011].

\subsection{Variation of Slip Rates in the Creeping Segment}

[49] Despite a greater sensitivity to noise than other regions and often insufficient data coverage, we observe notable variations of slip velocity in the creeping segment, as previously highlighted by Murray and Segall [2005] and Ryder and Bürgmann [2008]. To accommodate long-term relative motion between the North American and the Pacific plates, the area of slip deficit will have to accelerate eventually. Similarly, areas slipping at a larger velocity than plate rate must eventually slow down to satisfy the long-term slip rate. It is possible that these areas of accelerated and slower slip represent "ghost transients" [Hearn et al., 2011], i.e., periods of anomalous velocity that is longer than the period of observation. Long periods of transient deformation can be due to viscoelastic relaxation following large earthquakes. But at shallow depth, oscillatory slip velocity can be the result of spontaneous behavior of rate-and-state friction faults within a certain range of friction parameters [Ruina, 1983]. Velocity-weakening friction with relatively large critical nucleation size (the so-called $h^{*}$ parameter), which occurs under low effective confining pressure or large critical weakening distance can produce large excursions of velocity above and below plate rate without external perturbations [Ruina, 1983; Scholz, 1998; Lapusta and Barbot, 2012]. A better understanding of these processes will require a finer temporal coverage of the evolution of deformation for an extended period.

\section{Conclusions}

[50] The accumulation of geodetic measurements in the last 30 years in a broad region around the Parkfield segment of the San Andreas Fault allows us to compare the kinematic behavior of the fault at key periods of the earthquake cycle and to address fundamental questions about fault segmentation and the generation of earthquakes in the area.
[51] A combination of synthetic aperture radar and GPS measurements indicates that the Cholame and Parkfield segments formed a continuous domain of high coupling for at least 20 years before the $2004 M_{w} 6$ earthquake, consistent with previous analyses. However, the Parkfield $M_{w} 6$ earthquakes propagating southward terminated $20 \mathrm{~km}$ to the south into the locked zone without propagating into the Cholame segment. Additionally, the latest $M_{w} 6$ earthquake of 2004 initiated close to where previous events arrested, indicating a dramatic change in fault properties in this area.

[52] Analysis of geodetic data in the early stage of the interseismic period-after 2006, 2 years after the latest Parkfield earthquake - shows that the area of most coseismic slip during the 2004 rupture is now locked, singles out a large domain of low coupling south of the Parkfield segment, consistent with the presence of an obstacle between the Cholame and Parkfield segments, and demonstrates a pronounced segmentation of the San Andreas Fault into two separate domains at this latitude. The strong variations of velocity during the interseismic period is surprising and may be the result of a form of enhanced hardening during the interseismic period or perhaps more simply caused by the locked Cholame segment farther to the south.

[53] These observations indicate that the Parkfield seismogenic zone may be formed by a single area of velocity-weakening friction-with small enough critical nucleation size - surrounded north and south by fault estate with velocity-strengthening friction. This also implies that the stable distribution of microseismicity at Parkfield forms a marker for the transition of friction properties from weakening to strengthening. If this scenario holds in other regions, analysis of microseismicity in combination to geodesy may offer a great tool to map lateral variations of fault properties in active tectonic areas.

[54] Acknowledgments. P. Agram was supported by the Keck Institute of Space Studies Postdoctoral Fellowship. S. Barbot was funded by the Gordon and Betty Moore Foundation through grant GBMF 423.01 to the Caltech Tectonics Observatory and by grants from the Earth Observatory of Singapore.

\section{References}

Aster, R. C., B. Borchers, and C. H. Thurber (2012), Parameter Estimation and Inverse Problems, 2nd ed., 376 pp., Academic Press, Waltham, Mass., and Oxford, U. K.

Bakun, W., and T. McEvilly (1984), Recurrence models and Parkfield, California, earthquakes, J. Geophys. Res., 89(B5), 3051-3058.

Bakun, W. H., and A. G. Lindh (1985), The Parkfield, California, earthquake prediction experiment, Science, 229(4714), 619-624.

Bakun, W. H., et al. (2005), Implications for prediction and hazard assessment from the 2004 Parkfield earthquake, Nature, 437(7061), 969-974.

Barbot, S., Y. Fialko, and Y. Bock (2009), Postseismic deformation due to the $M_{w} 6.02004$ Parkfield earthquake: Stress-driven creep on a fault with spatially variable rate-and-state friction parameters, J. Geophys. Res., 114, B07405, doi:10.1029/2008JB005748.

Barbot, S., N. Lapusta, and J.-P. Avouac (2012), Under the hood of the earthquake machine: Toward predictive modeling of the seismic cycle, Science, 336(6082), 707-710.

Beeler, N. M., T. E. Tullis, and D. L. Goldsby (2008), Constitutive relationships and physical basis of fault strength due to flash heating, J. Geophys. Res., 113, B01401, doi:10.1029/2007JB004988.

Bell, M. A., J. R. Elliott, and B. E. Parsons (2011), Interseismic strain accumulation across the Manyi fault (Tibet) prior to the 1997 $\mathrm{M}_{w} 7.6$ earthquake, Geophys. Res. Lett., 38, L24302, doi:10.1029/ 2011GL049762.

Ben-Zion, Y., J. R. Rice, and R. Dmowska (1993), Interaction of the San Andreas fault creeping segment with adjacent great rupture zones 
and earthquake recurrence at Parkfield, J. Geophys. Res., 98(B2), 2135-2144, doi:10.1029/92JB02154.

Bennington, N., C. Thurber, K. Feigl, and J. Murray-Moraleda (2011), Aftershock distribution as a constraint on the geodetic model of coseismic slip for the 2004 Parkfield earthquake, Pure Appl. Geophys., $168,1553-1565$

Berardino, P., G. Fornaro, R. Lanari, and E. Sansosti (2002), A new algorithm for surface deformation monitoring based on small baseline differential SAR interferograms, IEEE Trans. Geosci. Remote Sens., 40(11), 2375-2383.

Bilek, S. L., and T. Lay (2002), Tsunami earthquakes possibly widespread manifestations of frictional conditional stability, Geophys. Res. Lett. 29(14), 1673, doi:10.1029/2002GL015215.

Bock, Y., et al. (1997), Southern California Permanent GPS Geodetic Array: Continuous measurements of regional crustal deformation between the 1992 Landers and 1994 Northridge earthquakes, J. Geophys. Res. 102(B8), 18,013-18,033.

Brantut, N., A. Schubnel, J.-N. Rouzaud, F. Brunet, and T. Shimamoto (2008), High-velocity frictional properties of a clay-bearing fault gouge and implications for earthquake mechanics, J. Geophys. Res., 113, B10401, doi:10.1029/2007JB005551.

Bruhat, L., S. Barbot, and J.-P. Avouac (2011), Evidence for postseismic deformation of the lower crust following the 2004 Mw6.0 Parkfield earthquake, J. Geophys. Res., 116, B08401, doi:10.1029/2010JB008073.

Burford, R. D., and P. W. Harsh (1980), Slip on the San Andreas Fault in central California from alignment array surveys, Bull. Seismol. Soc. Am., 70, 1233-1261.

Cavalié, O., C. Lasserre, M.-P. Doin, G. Peltzer, J. Sun, X. Xu, and Z.-K. Shen (2008), Measurement of interseismic strain across the Haiyuan fault (Gansu, China), by InSAR, Earth Planet. Sci. Lett., 275(3-4), 246-257.

Chen, C., and H. Zebker (2002), Phase unwrapping for large SAR interferograms: Statistical segmentation and generalized network models, IEEE Trans. Geosci. Remote Sens., 40(8), 1709-1719.

Custódio, S., P. Liu, and R. J. Archuleta (2005), The $2004 \mathrm{M}_{\mathrm{w}} 6.0$ Parkfield, California, earthquake: Inversion of near-source ground motion using multiple data sets, Geophys. Res. Lett., 32, L23312, doi:10.1029/2005GL024417.

d'Alessio, M. A., I. A. Johanson, R. Bürgmann, D. A. Schmidt, and M. H. Murray (2005), Slicing up the San Francisco Bay Area: Block kinematics and fault slip rates from GPS-derived surface velocities, J. Geophys. Res., 110, B06403, doi:10.1029/2004JB003496.

De Michele, M., D. Raucoules, F. Rolandone, P. Briole, J. Salichon, A Lemoine, and H. Aochi (2011), Spatiotemporal evolution of surface creep in the Parkfield region of the San Andreas Fault (1993-2004) from synthetic aperture radar, Earth Planet. Sci. Lett., 308(1-2), 141-150.

Dieterich, J. H. (1979), Modeling of rock friction: 1. Experimental results and constitutive equations, J. Geophys. Res., 84(B5), 2161-2168.

Dong, D., P. Fang, Y. Bock, F. Webb, L. Prawirodirdjo, S. Kedar, and P. Jamason (2006), Spatiotemporal filtering using principal component analysis and Karhunen-Loeve expansion approaches for regional GPS network analysis, J. Geophys. Res., 111, B03405, doi:10.1029/ 2005JB003806

Dziewoński, A. M., and D. L. Anderson (1981), Preliminary reference earth model, Phys. Earth Planet. Inter, 25(4), 297-356.

Elliott, J. R., J. Biggs, B. Parsons, and T. J. Wright (2011), InSAR slip rate determination on the Altyn Tagh Fault, northern Tibet, in the presence of topographically correlated atmospheric delays, Geophys. Res. Lett., 35 L12309, doi:10.1029/2008GL033659.

Faulkner, D. R., T. M. Mitchell, J. Behnsen, T. Hirose, and T. Shimamoto (2011), Stuck in the mud? Earthquake nucleation and propagation through accretionary forearcs, Geophys. Res. Lett., 38, L18303, doi:10.1029/2011GL048552.

Fay, N. P., and E. D. Humphreys (2005), Fault slip rates, effects of elastic heterogeneity on geodetic data, and the strength of the lower crust in the Salton Trough region, Southern California, J. Geophys. Res., 110, B09401, doi:10 1029/2004JB003548.

Fialko, Y. (2006), Interseismic strain accumulation and the earthquake potential on the southern San Andreas Fault system, Nature, 441, 968-971.

Fukuyama, E., and K. Mizoguchi (2010), Constitutive parameters for earthquake rupture dynamics based on high-velocity friction tests with variable sliprate, Int. J. Fract., 163(1-2), 15-26.

Goldstein, R. M., and C. L. Werner (1998), Radar interferogram filtering for geophysical applications, Geophys. Res. Lett., 25(21), 4035-4038.

Harris, R. A., and P. Segall (1987), Detection of a locked zone at depth on the Parkfield, California, segment of the San Andreas Fault, J. Geophys. Res., 92(B8), 7945-7962.

Hearn, E. H., F. F. Pollitz, W. R. Thatcher, and C. T. Onishi (2011), "Ghost transients" in the southern California GPS velocity field: An investigation using finite-fault earthquake cycle models, Abstract \#T23C-2409 presented at 2011 Fall Meeting, AGU, San Francisco, Calif.
Herring, T. A. (1999), Geodetic applications of GPS, Proc. IEEE, 87(1), $92-110$.

Hetland, E. A., P. Musé, M. Simons, Y. N. Lin, P. S. Agram, and C. J. DiCaprio (2012), Multiscale InSAR Time Series (MInTS) analysis of surface deformation, J. Geophys. Res., 117, B02404, doi:10.1029/ 2011JB008731.

Hill, E. M., J. L. Davis, P. Elòsegui, B. P. Wernicke, E. Malikowski, and N. A. Niemi (2009), Characterization of site-specific GPS errors using a short-baseline network of braced monuments at Yucca Mountain, southern Nevada, J. Geophys. Res., 114, B11402, doi:10.1029/ 2008JB006027.

Hillers, G., Y. Ben-Zion, and P. M. Mai (2006), Seismicity on a fault controlled by rate- and state-dependent friction with spatial variations of the critical slip distance, J. Geophys. Res., 111, B01403, doi:10.1029/ 2005JB003859.

Huiskamp, G. (1991), Difference formulas for the surface Laplacian on a triangulated surface, J. Comput. Phys., 95(2), 477-496.

Ito, Y., K. Obara, K. Shiomi, S. Sekine, and H. Hirose (2007), Slow earthquakes coincident with episodic tremors and slow slip events, Science, $315,503-506$.

Johanson, I. A., and R. Bürgmann (2005), Creep and quakes on the northern transition zone of the San Andreas fault from GPS and InSAR data, Geophys. Res. Lett., 32, L14306, doi:10.1029/2005GL023150.

Johanson, I. A., and R. Bürgmann (2010), Coseismic and postseismic slip from the 2003 San Simeon earthquake and their effects on backthrust slip and the 2004 Parkfield earthquake, J. Geophys. Res., 115, B07411, doi: 10.1029/2009JB006599.

Johanson, I. A., E. J. Fielding, F. Rolandone, and R. Bürgmann (2006), Coseismic and postseismic slip of the 2004 Parkfield earthquake from space-geodetic data, Bull. Seismol. Soc. Am., 96(4B), S269-S282.

Johnson, K. M., and P. Segall (2004), Viscoelastic earthquake cycle models with deep stress-driven creep along the San Andreas fault system, $J$ Geophys. Res., 109, B10403, doi:10.1029/2004JB003096.

Jolivet, R., R. Cattin, N. Chamot-Rooke, C. Lasserre, and G. Peltzer (2008), Thin-plate modeling of interseismic deformation and asymmetry across the Altyn Tagh fault zone, Geophys. Res. Lett., 35, L02309, doi:10.1029/2007GL031511.

Jolivet, R., C. Lasserre, M.-P. Doin, S. Guillaso, G. Peltzer, R. Dailu, J. Sun, Z.-K. Shen, and X. Xu (2012), Shallow creep on the Haiyuan Fault (Gansu, China) revealed by SAR Interferometry, J. Geophys. Res., 117, B06401, doi:10.1029/2011JB008732.

Kaneko, Y., J.-P. Avouac, and N. Lapusta (2010), Towards inferring earthquake patterns from geodetic observations of interseismic coupling, Nat. Geosci., 3, 363-369.

Kositsky, A. P., and J.-P. Avouac (2010), Inverting geodetic time series with a principal component analysis-based inversion method, J. Geophys. Res., 115, B03401, doi:10.1029/2009JB006535.

Landry, W., S. Barbot, and K. Chanard (2012), Gamra: Simple Earth models for complex Earth models, Abstract DI13C-2438, Fall Meeting, AGU, Washington, D. C.

Langbein, J. (2008), Noise in GPS displacement measurements from Southern California and Southern Nevada, J. Geophys. Res., 113, B05405, doi:10.1029/2007JB005247.

Lapusta, N., and S. Barbot (2012), Models of earthquakes and aseismic slip based on laboratory-derived rate and state friction laws, in The Mechanics of Faulting: From Laboratory to Real Earthquakes, edited by A. Bizzarri and H. S. Bhat, 55 pp., Research Signpost, Kerala, India.

Lapusta, N., and Y. Liu (2009), Three-dimensional boundary integral modeling of spontaneous earthquake sequences and aseismic slip, J. Geophys. Res., 114, B09303, doi:10.1029/2008JB005934.

Lapusta, N., J. R. Rice, Y. BenZion, and G. Zheng (2000), Elastodynamics analysis for slow tectonic loading with spontaneous rupture episodes on faults with rate- and state-dependent friction, J. Geophys. Res., 105(B10), 23,765-23,789

Lindsey, E and Y Fialko (2013), Geodetic slip rates in the southern San Andreas Fault system: Effects of elastic heterogeneity and fault geometry, J. Geophys. Res. Solid Earth, 118, 689-697, doi:10.1029/ 2012JB009358.

Liu, Y., and J. R. Rice (2005), Aseismic slip transients emerge spontaneously in three-dimensional rate and state modeling of subduction earthquake sequences, J. Geophys. Res., 110, B08307, doi:10.1029/2004JB003424.

Lundgren, P., E. A. Hetland, Z. Liu, and E. J. Fielding (2009), Southern San Andreas-San Jacinto fault system slip rates estimated from earthquake cycle models constrained by GPS and interferometric synthetic aperture radar observations, J. Geophys. Res., 114, B02403, doi:10.1029/2008JB005996.

Ma, S., S. Custódio, R. J. Archuleta, and P. Lui (2008), Dynamic modeling of the $2004 \mathrm{M}_{\mathrm{w}}$ 6.0 Parkfield, California, earthquake, J. Geophys. Res. 113, B02301, doi:10.1029/2007JB005216. 
Marone, C., C. H. Scholz, and R. Bilham (1991), On the mechanics of earthquake afterslip, J. Geophys. Res., 96, 8441-8452.

Marone, C. J. (1998), Laboratory-derived friction laws and their application to seismic faulting, Annu. Rev. Earth Planet. Sci., 26, 643-696.

Miyazaki, S., P. Segall, J. J. McGuire, T. Kato, and Y. Hatanaka (2006), Spatial and temporal evolution of stress and slip rate during the 2000 Tokai slow earthquake, J. Geophys. Res., 111, B03409, doi:10.1029/ 2004JB003426.

Murray, J., and J. Langbein (2006), Slip on the San Andreas Fault at Parkfield, California, over two earthquake cycles, and the implications for seismic hazard, Bull. Seismol. Soc. Am., 96(4B), S283-S303.

Murray, J. R., and P. Segall (2005), Spatiotemporal evolution of a transient slip event on the San Andreas fault near Parkfield, California, J. Geophys. Res., 110, B09407, doi:10.1029/2005JB003651.

Murray, J. R., P. Segall, P. Cervelli, W. Prescott, and J. Svarc (2001), Inversion of GPS data for spatially variable slip-rate on the San Andreas Fault near Parkfield, CA, Geophys. Res. Lett., 28(2), 359-362.

Nakatani, M., and C. H. Scholz (2004), Frictional healing of quartz gouge under hydrothermal conditions: 2. Quantitative interpretation with a physical model, J. Geophys. Res., 109, B07202, doi:10.1029/2003JB002938.

Niu, F., P. G. Silver, R. M. Nadeau, and T. V. McEvilly (2003), Migration of seismic scatterers associated with the 1993 Parkfield aseismic transient event, Nature, 426, 544-548.

Noda, H. (2008), Frictional constitutive law at intermediate slip rates accounting for flash heating and thermally activated slip process, $J$. Geophys. Res., 113, B09302, doi:10.1029/2007JB005406.

Pritchard, M. E., M. Simons, P. A. Rosen, S. Hensley, and F. H. Webb (2002), Co-seismic slip from the 1995 July $30 M_{w}=8.1$ Antofagasta, Chile, earthquake as constrained by InSAR and GPS observations, Geophys. J. Int., 150(2), 362-376.

Rice, J. R. (1993), Spatio-temporal complexity of slip on a fault, J. Geophys. Res., 98(B6), 9885-9907.

Rice, J. R., and A. L. Ruina (1983), Stability of steady frictional slipping, J. Appl. Mech., 50, 343-349.

Rice, J. R., N. Lapusta, and K. Ranjith (2001), Rate and state dependent friction and the stability of sliding between elastically deformable solids, J. Mech. Phys. Solids, 49, 1865-1898.

Roeloffs, E., and J. Langbein (1994), The earthquake prediction experiment at Parkfield, California, Rev. Geophys., 32(3), 315-336.

Rogers, G., and H. Dragert (2003), Episodic tremor and slip on the Cascadia subduction zone: The chatter of silent slip, Science, 300(5627), 1942-1943, doi:10.1126/science.1084783.

Rolandone, F., R. Bürgmann, D. C. Agnew, I. A. Johanson, D. C. Templeton, M. A. d'Alessio, S. J. Titus, C. DeMets, and B. Tikoff (2008), Aseismic slip and fault-normal strain along the central creeping section of the San Andreas fault, Geophys. Res. Lett., 35, L14305, doi:10.1029/2008GL034437.

Rosen, P. A., S. Henley, G. Peltzer, and M. Simons (2004), Updated repeat orbit interferometry package released, Eos Trans. AGU, 85(5), 47.

Rubin, A. M. (2008), Episodic slow slip events and rate-and-state friction, J. Geophys. Res., 113, B11414, doi:10.1029/2008JB005642.

Ruina, A. (1983), Slip instability and state variable friction laws, J. Geophys. Res., 88, 10,359-10,370.

Ryder, I., and R. Bürgmann (2008), Spatial variations in slip deficit on the central San Andreas Fault from InSAR, Geophys. J. Int., 175(3), $837-852$.

Scholz, C. H. (1998), Earthquakes and friction laws, Nature, 391, $37-42$.

Segall, P. (2010), Earthquake and Volcano Deformation, Princeton Univ. Press, Princeton, N. J.

Segall, P., and Y. Du (1993), How similar were the 1934 and 1966 Parkfield earthquakes?, J. Geophys. Res., 98, 4527-4538.

Segall, P., and R. A. Harris (1987), Earthquake deformation cycle on the San Andreas Fault near Parkfield, California, J. Geophys. Res., 92(B10), 10,511-10,525.

Segall, P., A. M. Rubin, A. M. Bradley, and J. R. Rice (2010), Dilatant strengthening as a mechanism for slow slip events, J. Geophys. Res., 115, B12305, doi: $10.1029 / 2010 J B 007449$.

Shen, Z.-K., R. W. King, D. C. Agnew, M. Wang, T. A. Herring, D. Dong, and P. Fang (2011), A unified analysis of crustal motion in Southern California, 1970-2004: The SCEC crustal motion map, J. Geophys. Res., 116, B11402, doi:10.1029/2011JB008549.
Shibazaki, B., T. Matsuzawa, A. Tsutsumi, K. Ujiie, A. Hasegawa, and Y. Ito (2011), 3D modeling of the cycle of a great Tohoku-oki earthquake, considering frictional behavior at low to high slip velocities, Geophys. Res. Lett., 38, L21305, doi:10.1029/2011GL049308.

Sieh, K. (1978a), Slip along the San Andreas Fault associated with the great 1857 earthquake, Bull. Seismol. Soc. Am., 68(5), 1421-1448.

Sieh, K. (1978b), Central California foreshocks of the great 1857 earthquake, Bull. Seismol. Soc. Am., 68(8), 1731-1749.

Sieh, K. E., and R. H. Jahns (1984), Holocene activity of the San Andreas Fault at Wallace Creek, California, Geology, 95, 883-896.

Sone, H., and T. Shimamoto (2009), Frictional resistance of faults during accelerating and decelerating earthquake slip, Nat. Geosci., 2, 705-708.

Tape, C., Q. Liu, A. Maggi, and J. Tromp (2009), Adjoint tomography of the southern California crust, Science, 325, 988-992.

Thatcher, W. (1979), Systematic inversion of geodetic data in Central California, J. Geophys. Res., 84(B5), 2283-2295.

Thurber, C., H. Zhang, F. Waldhauser, J. Hardebeck, A. Michael, and D Eberhat-Phillips (2006), Three-dimensional compressional wavespeed model, Earthquake relocation, and focal mechanisms for the Parkfield, California, region, Bull. Seismol. Soc. Am., 96(4B), S38-S49.

Toké, N. A., J. R. Arrowsmith, M. J. Rymer, A. Landgraf, D. E. Haddad, M. Busch, J. Coyan, and A. Hannah (2011), Late Holocene slip rate of the San Andreas fault and its accommodation by creep and moderatemagnitude earthquakes at Parkfield, California, Geology, 39(3), 243-246.

Toppozada, T. R., D. M. Branum, M. S. Reichle, and C. L. Hallstrom (2002), San Andreas Fault zone, California: $M \geq 5.5$ earthquake history, Bull. Seismol. Soc. Am. 92(7), 2555-2601.

Toro, G. D., D. L. Goldsby, and T. E. Tullis (2004), Friction falls towards zero in quartz rock as slip velocity approaches seismic rates, Nature, 427 , 436-439.

Tse, S. T., and J. R. Rice (1986), Crustal earthquake instability in relation to the depth variation of frictional slip properties, J. Geophys. Res., 91(B9), 9452-9472.

Uchide, T., S. Ide, and G. C. Beroza (2009), Dynamic high-speed rupture from the onset of the 2004 Parkfield, California, earthquake, Geophys. Res. Lett., 36, L04307, doi:10.1029/2008GL036824.

Waldhauser, F., W. L. Ellsworth, D. P. Schaff, and A. Cole (2004), Streaks, multiplets, and holes: High-resolution spatio-temporal behavior of Parkfield seismicity, Geophys. Res. Lett., 31, L18608, doi:10.1029/ 2004 GL020649.

Wang, H., T. J. Wright, and J. Biggs (2009), Interseismic slip rate of the northwestern Xianshuihe fault from InSAR data, Geophys. Res. Lett., 36, L03302, doi:10.1029/2008GL036560.

Wang, R., F. Martin, and F. Roth (2003), Computation of deformation induced by earthquakes in a multi-layered elastic crust-FORTRAN programs EDGRN/EDCMP, Comput. Geosci., 29, 195-207.

Wdowinkski, S., Y. Bock, J. Zhang, P. Fang, and J. Genrich (1997), Southern California permanent GPS geodetic array: Spatial filtering of daily positions for estimating coseismic and postseismic displacements induced by the 1992 Landers earthquake, J. Geophys. Res., 102(B8), $18,057-18,070$.

Wesnousky, S. G. (1986), Earthquakes, quaternary faults, and seismic hazard in California, J. Geophys. Res., 91(B12), 12,587-12,631.

Williams, S. D. P., Y. Bock, P. Fang, P. Jamason, R. M. Nikolaidis, L. Prawirodirdjo, M. Miller, and D. J. Johnson (2004), Error analysis of continuous GPS position time series, J. Geophys. Res., 109, B03412, doi:10.1029/2003JB0022741.

Wood, H. O. (1955), The 1857 earthquake in California, Bull. Seismol. Soc. Am., 45, 47-67.

Wright, T. J., B. Parsons, P. C. England, and E. J. Fielding (2004), InSAR observations of low slip rates on the major faults of western Tibet Science, 305(5681), 236-239.

Young, J. J., J. R. Arrowsmith, L. Colini, L. B. Grant, and B. Gootee (2002), Three-dimensional excavation and recent rupture history along the cholame segment of the San Andreas fault, Bull. Seismol. Soc. Am. 92(7), 2670-2688.

Zebker, H., S. Hensley, P. Shanker, and C. Wortham (2010), Geodetically accurate InSAR data processor, IEEE Trans. Geosci. Remote Sens., 48(12), 4309-4321.

Ziv, A. (2012), Inference of coseismic slip via joint inversion of GPS and aftershock data: The 2004 Parkfield example, J. Geophys. Res., 117, B03307, doi:10.1029/2011JB008400. 